\title{
Towards a New Approach for Evaluating Fire Blocking Barrier Fabrics
}

Shonali Nazaré

William Pitts

Shaun Flynn

John. R. Shields

Rick D. Davis

http://dx.doi.org/10.6028/NIST.TN.1798

April 2013

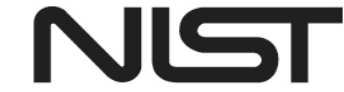

National Institute of Standards and Technology

U.S. Department of Commerce 


\section{Towards a New Approach for Evaluating Fire Blocking Barrier Fabrics}

Shonali Nazaré

William Pitts

Shaun Flynn

John. R. Shields

Rick D. Davis

Fire Research Division

Engineering Laboratory

http://dx.doi.org/10.6028/NIST.TN.1798

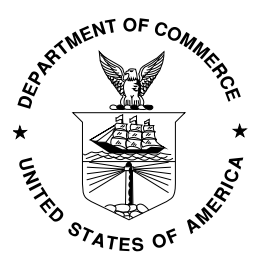

U.S. Department of Commerce

Rebecca M. Blank, Acting Secretary

National Institute of Standards and Technology Patrick D. Gallagher, Under Secretary of Commerce for Standards and Technology and Director 
Certain commercial entities, equipment, or materials may be identified in this document in order to describe an experimental procedure or concept adequately. Such identification is not intended to imply recommendation or endorsement by the National Institute of Standards and Technology, nor is it intended to imply that the entities, materials, or equipment are necessarily the best available for the purpose.

National Institute of Standards and Technology Technical Note 1798

Natl. Inst. Stand. Techn. Techn. Note 1798, 35 pages (April 2013)

http://dx.doi.org/10.6028/NIST.TN.1798

CODEN: NTNOEF 


\begin{abstract}
The objective of this study was to provide guidelines to quantify heat transfer characteristics of fire blocking barrier fabrics (BF) used in soft furnishings. Fundamental BF properties that influence the heat transfer characteristics as it relates to thermal protection of cushioning components in upholstered products are discussed. This is important to enable a priori selection of BFs such that a final upholstered product complies with full-scale, open-flame flammability regulations. The report provides a brief review of existing test methods which generally use char length and/or mass loss as "pass/fail" criteria for assessing performance of BFs to be used in finished products. Generally, in these test methods, BFs are tested in mock-up configuration as opposed to individual components as considered in this study.
\end{abstract}

Basic heat transfer measurements are used to determine effectiveness of materials to be used as BFs. The document includes descriptions of flammability test methods used to characterize the ignitability, heat release rate, and heat transfer properties of BFs. Selected BFs have been examined for the aforementioned properties, and results are discussed. A new bench-scale composite test method is also described to assess qualitative performance of BFs. When tested for heat transfer characteristics, the area density and thickness of BFs show strong influence. However, when tested as a composite in a mock-up assembly, the BFs considered in this study showed a clear distinction between active and passive BFs. In the case of chemically active BFs, the construction parameters and material properties such as thickness, air permeability, and heat transfer were of little significance. In the case of passive BFs, however, these parameters became decisive. Results from this study suggest that if the BF is not an active fire barrier, then the amount of heat transferred through BF is critical, i.e, the material should be thermally thick to protect the underlying cushioning layers.

This document is intended to be a technical resource that provides a holistic approach to quantify the fire performance properties of BFs used in soft furnishings. As such, it does not provide a minimum standard for barrier materials.

\title{
Keywords
}

barrier fabrics; soft furnishings; upholstered furniture; mattress; flammability; bench-scale tests, thermal protective performance, heat release rate, thermal degradation 
This page left intentionally blank 


\section{Contents}

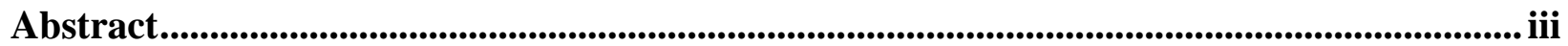

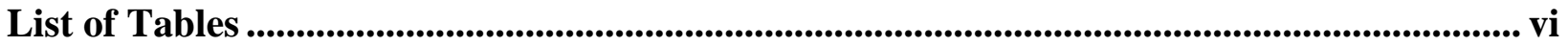

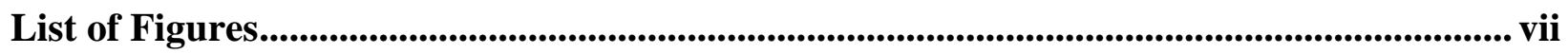

List of Acronyms and Abbreviations ........................................................................................ viii

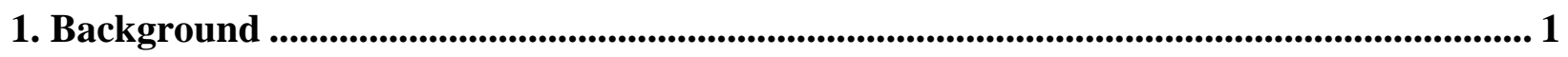

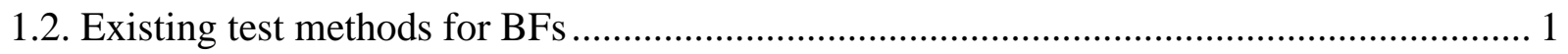

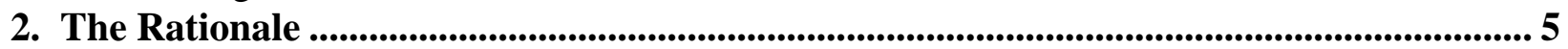

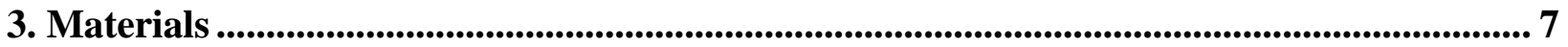

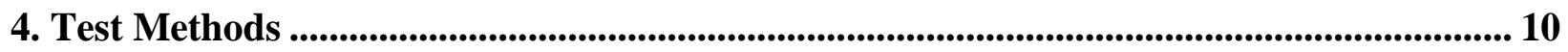

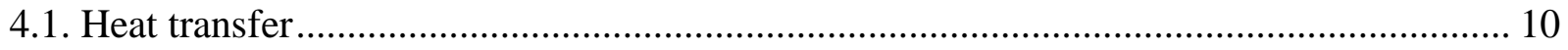

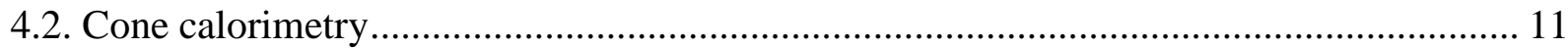

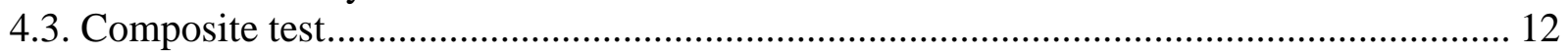

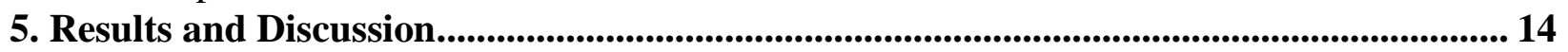

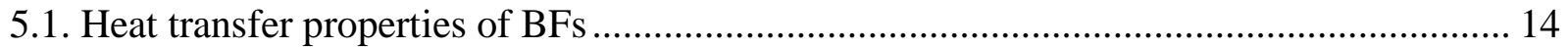

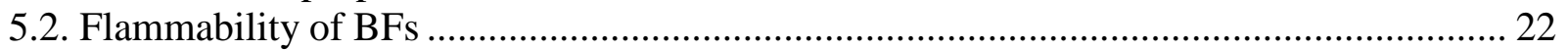

5.3. Burning behavior of composite assemblies .............................................................. 24

6. Concluding Remarks and Future Work ................................................................................ 31

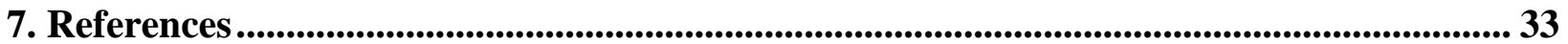


List of Tables

Table 1. Standards and test methods for assessing ignitability of BFs.

Table 2. Description of BFs used in soft furnishings. Uncertainties are reported as Type A uncertainties with experimental standard deviations..

Table 3. Heat transfer characteristics of BFs used in soft furnishings. Uncertainties are reported as Type A uncertainties with experimental standard deviations.

Table 4. Flammability properties of BFs under fully-ventilated conditions in the cone calorimeter . Uncertainties in measurement of PHRR and THR are reported as Type A uncertainties with experimental standard deviations.

Table 5. Digital images of composite samples with active BFs exposed to $40 \mathrm{~mm}$ butane flame for $20 \mathrm{~s}$.

Table 6. Digital images of composite samples with passive BFs exposed to $40 \mathrm{~mm}$ butane flame for $20 \mathrm{~s}$. 
List of Figures

Figure 1. Mock-up arrangement for UFAC smoldering ignition testing of BFs used in upholstered furniture.

Figure 2. ASTM D 5238 test for smoldering ignition resistance of cotton batting: (a) start, (b) test in progress, and (c) end of the test. Cotton batting stack on left of (a) is placed on top of the cigarette/cotton batting stack on the right of (a) to form the testing setup in (b).. 3 Figure 3. Schematic of ASTM D 7140 test method for BFs.

Figure 4. Modified Cal TB 117 for testing barrier flammability: (a) vertical and (b) horizontal configuration. 5

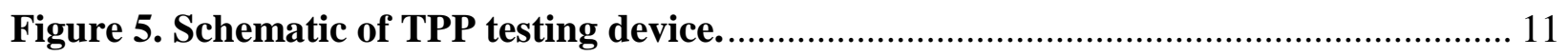

Figure 6. Specimen assembly for cone calorimetry experiments. ..................................... 12

Figure 7. Vertical flammability test rig developed for the 'Mydrin' test. .......................... 13

Figure 8. Correlation between TPP and thickness of BFs. Uncertainties are reported as Type A uncertainties with experimental standard deviations. .......................................... 15

Figure 9. Correlation between THT and TPP ratings of BFs. Uncertainties are reported as Type A uncertainties with experimental standard deviations. .......................................... 15

Figure 10. Thermal response of woven and knitted BFs.............................................. 16

Figure 11. Thermal response of nonwoven BFs...................................................... 17

Figure 12. Correlation between THT and area density of the BFs. Uncertainties are reported as Type A uncertainties with experimental standard deviations. 19

Figure 13. Correlation between THT and thickness of the BFs. Uncertainties are reported as Type A uncertainties with experimental standard deviations 20

Figure 14. Ranking of BFs using thermal protective indices............................................ 22 


\section{List of Acronyms and Abbreviations}

\begin{tabular}{|c|c|}
\hline ANPR & Announced Proposal of Rulemaking \\
\hline $\mathrm{BF}$ & Barrier Fabric \\
\hline BHFTI & California Bureau of Home Furnishings and Thermal Insulation \\
\hline CAL TB & California Test Bulletin \\
\hline CFR & Code of Federal Regulations \\
\hline CPSC & Consumer Product Safety Commission \\
\hline FIGRA & Fire Growth Rate \\
\hline FO & Flame out (s) \\
\hline FR & Flame Resistant \\
\hline HRR & Heat Release Rate $\left(\mathrm{kW} / \mathrm{m}^{2}\right)$ \\
\hline HTP & Heat Transfer Properties \\
\hline HTF & Heat Transfer Factor \\
\hline IR & Infrared \\
\hline LOI & Limiting Oxygen Index ( oxygen fraction) \\
\hline NIST & National Institute of Standards and Technology \\
\hline PHRR & Peak Heat Release Rate $\left(\mathrm{kW} / \mathrm{m}^{2}\right)$ \\
\hline PUF & Polyurethane Foam \\
\hline SPUF & Standard Polyurethane Foam \\
\hline THR & Total Heat Released $\left(\mathrm{MJ} / \mathrm{m}^{2}\right)$ \\
\hline THT & Total Heat Transferred (MJ) \\
\hline TPI & Thermal Protective Index; the inverse of HTF ( ) \\
\hline ТPP & Thermal Protective Performance $\left(\mathrm{cal} / \mathrm{cm}^{2}\right)$ \\
\hline TPT & Thermal Protective Temperature $\left({ }^{\circ} \mathrm{C}\right)$ \\
\hline $\mathrm{TPF}$ & Thermal Protective Factor \\
\hline TTP & Time to Peak (s) \\
\hline RUF & Residential Upholstered Furniture \\
\hline UFAC & Upholstered Furniture Action Council \\
\hline Second & $\mathrm{S}$ \\
\hline Joule & $\mathrm{J}$ \\
\hline Watt & $\mathrm{W}$ \\
\hline
\end{tabular}




\section{Background}

The federal flammability regulation (16 CFR Part 1633 [1]) for residential mattresses, enacted in 2007 by the U.S. Consumer Product Safety Commission (CPSC), generated much interest in understanding the burning behavior of mattresses as well as in developing new materials for mattress construction. To comply with this open flame regulation, mattress manufacturers predominantly use fire blocking barrier materials [2]. Currently, there is no federal flammability regulation for residential upholstered furniture (RUF), but CPSC has proposed a regulation (CPSC 16 CFR part 1634 [3]) that defines a smoldering and open flame metric for these products. One option to comply with the proposed 16 CFR Part 1634 is to incorporate a barrier material, also called barrier fabric (BF), that has passed smolder and open flame ignition tests, into the RUF. BFs are expected to play an increasingly important role in reducing the fire hazard of soft furnishings.

Strategically placed between the cover fabric (known as ticking in the case of a mattress) and the cushioning layer, the purpose of fire blocking BFs is to reduce the flammability of soft furnishings by preventing or delaying direct flame impingement and heat transfer from open flames and smoldering cigarettes to the more flammable core cushioning components. In order to protect underlying flammable polyurethane foam (PUF), the BF should not ignite, or should be self-extinguishing; the BF should provide insulation against the heat released from burning of outer layers of upholstery; and the BF should remain intact when exposed to heat and/or flames. There are a significant number of commercial fire blocking technologies available to accommodate the vast requirements of consumers, manufacturers, and regulatory agencies. In order to accomplish comprehensive understanding of the BFs available in the market and their performance attributes required to comply with the current 16 CFR part 1633 regulation, NIST reviewed [4] several fire blocking technologies, their effectiveness, and potential test methods for characterizing heat transfer. The heat transfer properties are a key aspect of BF performance. The review [4] discusses various fire blocking technologies with respect to material type, fiber content, and fire blocking mechanisms. The review suggested that successfully achieving the desired level of fire protection requires appropriate matching of the BF to the desired characteristics of the soft furnishing. Moreover, very little is known about fire performance requirements of these BFs that are critical to comply with full-scale fire regulations for mattresses and upholstered furniture, which makes a priori selection of fire barrier materials difficult. Selection of BFs is therefore a process of trial and error with current test methods that do not quantify barrier effectiveness in terms of thermal protection, gas permeability, structural integrity and residual strength, ability to extinguish, and/or lower the temperature of flames. Current test methods for BFs are tested in mock-up configurations as opposed to quantification of an individual component.

\subsection{Existing test methods for BFs}

Various test methods that are used to assess smoldering ignitability of BFs are listed in Table 1. All test methods essentially require testing of a barrier component sandwiched between a standard polyurethane foam (SPUF) and smolder prone cover fabrics (Class II cover fabrics [5]). The smoldering ignition assessment of a barrier component, as described in test methods listed in Table 1, is conducted on a small scale mock-up composite (Figure 1) and is voluntarily used by 
many upholstered furniture and fabric manufacturers. The mock-up consists of a wooden frame, a SPUF, BF, cover fabric, and a cigarette under a sheeting material. This test is based on the British standard BS 5852 part I test method [6] for the ignitability of an upholstered furniture composite when exposed to a smoldering ignition source (Source 0 in the BS 5852) [3]. However, the pass/fail criteria or the classification norms vary with the standardizing authorities. The barrier test method (Method 3 [7]) defined by the Upholstered Furniture Action Council (UFAC) specifies a maximum char length of $38 \mathrm{~mm}$. The BF fails if the composite ignites or the vertical char length exceeds $38 \mathrm{~mm}$ upward from the crevice [7]. The ASTM E1353 [8], standard test method for cigarette ignition resistance of components of upholstered furniture, classifies BFs based on a critical char length of $51 \mathrm{~mm}$. According to the ASTM E1353, BFs with char length of $51 \mathrm{~mm}$ or less are classified as Class A barriers and those which ignite or have char length in excess of $51 \mathrm{~mm}$ are classified as Class B barriers. The NFPA 260 [9] classifies barrier materials as Class I or Class II based on char length similar to that prescribed by ASTM E1353.

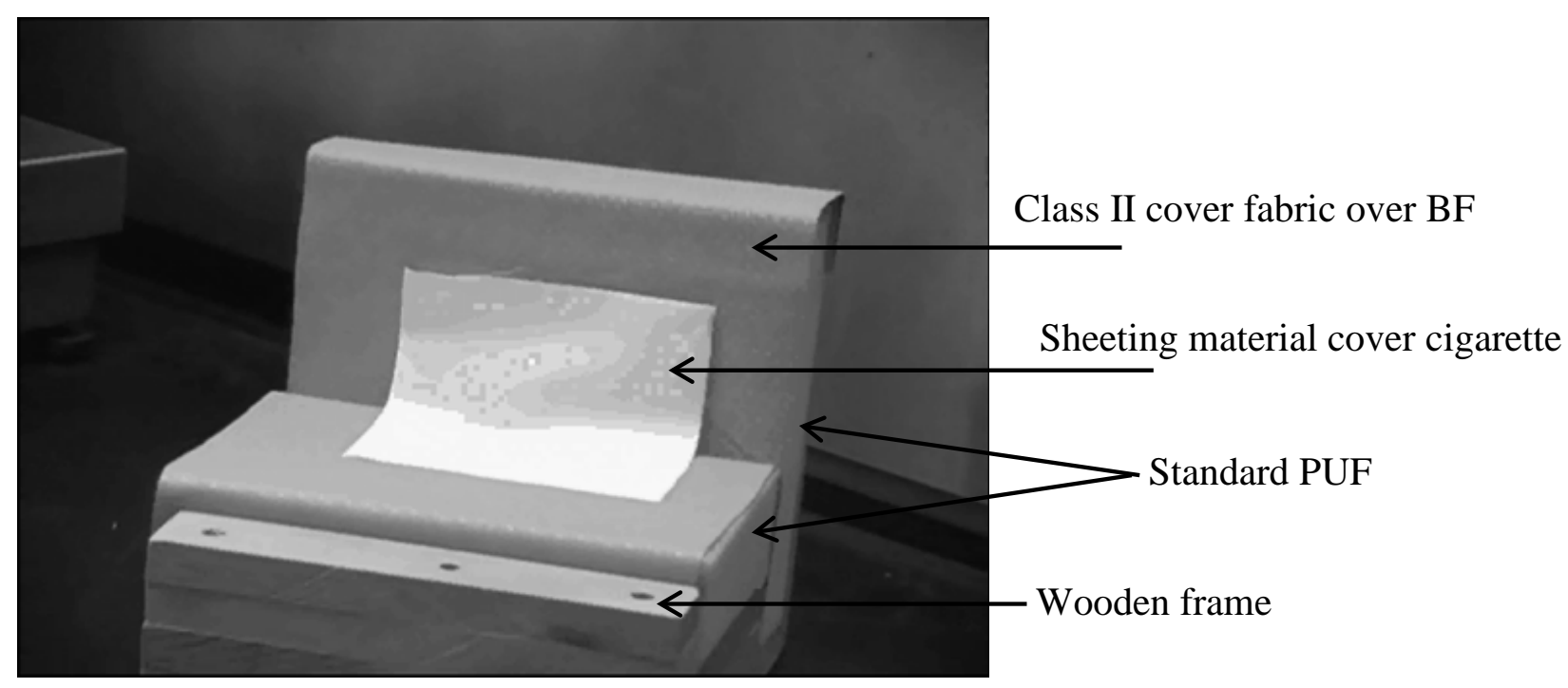

Figure 1. Mock-up arrangement for UFAC smoldering ignition testing of BFs used in upholstered furniture.

The barrier test described in the proposed 16 CFR part 1634 uses mass loss as its 'pass/fail' criteria as opposed to a char length criteria as in the UFAC and similar barrier test [7]. The BF, when tested with a cotton velvet cover fabric (a smolder prone fabric), passes the test if the mass loss of SPUF is less than $1 \%$ and the mock-up does not transition to flaming during the 45 min test duration.

ASTM had a barrier component test (now withdrawn) to assess the smoldering ignition resistance of cotton battings. In the ASTM D5238 [10] test method a lighted cigarette was placed between precut and preconditioned pieces of cotton battings (Figure 2), and the length of char was measured as soon as smoke was observed. Failure was defined as char lengths of $25.4 \mathrm{~mm}$ (1 inch) or greater. Boric acid treated cotton battings generally passed this test [11]. 
Table 1. Standards and test methods for assessing ignitability of BFs.

\begin{tabular}{|c|c|c|c|}
\hline $\begin{array}{l}\text { Issuing } \\
\text { authority }\end{array}$ & $\begin{array}{l}\text { Standard } \\
\text { [reference] }\end{array}$ & $\begin{array}{l}\text { Type of } \\
\text { ignition }\end{array}$ & Pass/fail/classification criteria. \\
\hline UFAC & UFAC Method 3 [7] & Smoldering & - Vertical char length $<38 \mathrm{~mm}$. \\
\hline NFPA & NFPA 260 [9] & Smoldering & $\begin{array}{l}\text { - Class I barrier material: Vertical char length }<51 \mathrm{~mm} \text {. } \\
\text { - Class II barrier material: Vertical char length }>51 \mathrm{~mm}\end{array}$ \\
\hline ASTM & ASTM_E-1353 [8] & Smoldering & $\begin{array}{l}\text { - Class A barrier material: Vertical char length }<51 \mathrm{~mm} \text {. } \\
\text { - Class B barrier material: Vertical char length }>51 \mathrm{~mm} \text {. }\end{array}$ \\
\hline ASTM & ASTM D-5238 [10] & Smoldering & - $\quad$ Char length < $25.4 \mathrm{~mm}$. \\
\hline CPSC & $\begin{array}{l}\text { 16 CFR Part1634 } \\
\text { (proposed) [3] }\end{array}$ & Smoldering & $\begin{array}{l}\text { - No transition into flaming during } 45 \text { min test duration. } \\
\text { - SPUF mass loss }<1 \% \text {. }\end{array}$ \\
\hline BHFTI & Cal TB 117 [12] & Smoldering & $\begin{array}{l}\text { - No smoldering after the } 45 \text { min test duration. } \\
\text { - No transition into flaming during } 45 \text { min test duration. } \\
\text { - Char length }<50 \mathrm{~mm} \text {. }\end{array}$ \\
\hline BHFTI & Cal TB 116 [13] & Smoldering & $\begin{array}{l}\text { - No transition into flaming during test duration. } \\
\text { - Char length }<51 \mathrm{~mm} \text {. }\end{array}$ \\
\hline ASTM & ASTM D-7140 [14] & Flaming & - Heat penetration (qualitative). \\
\hline
\end{tabular}

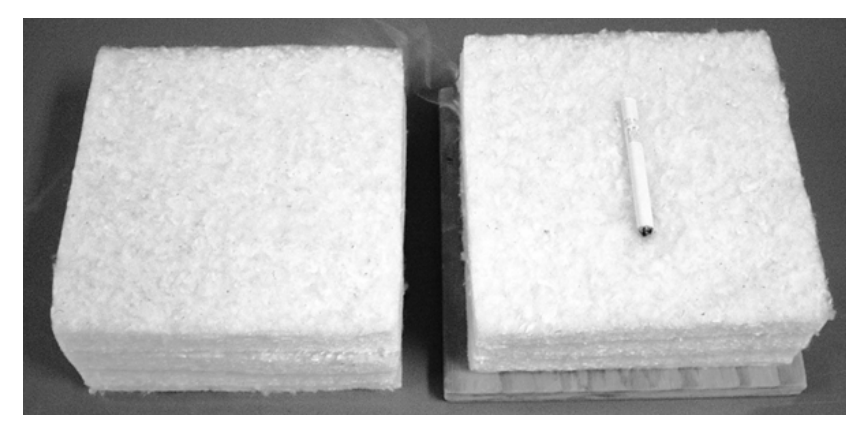

(a)

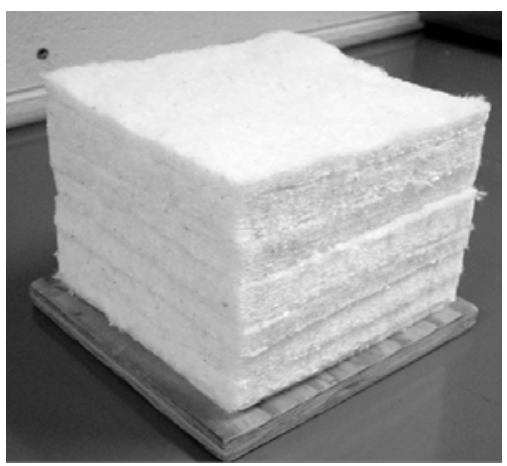

(b)

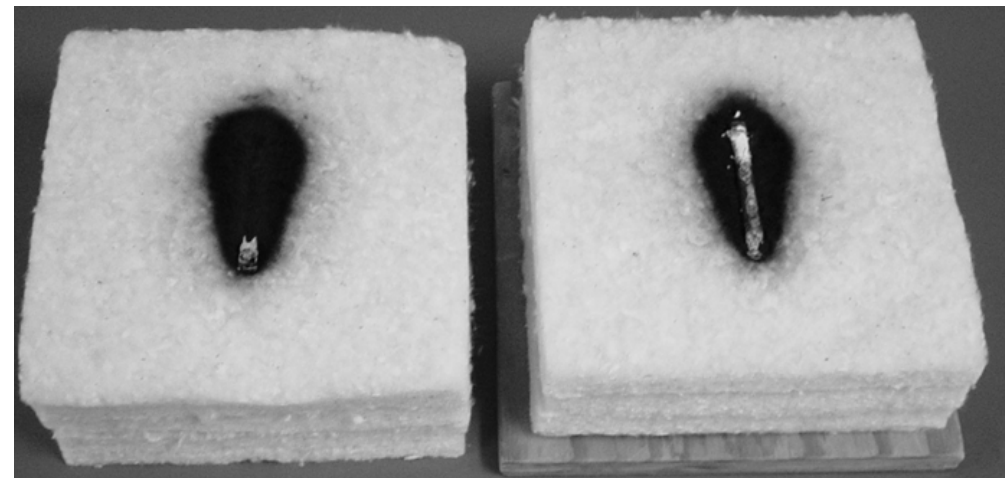

(c)

Figure 2. ASTM D 5238 test for smoldering ignition resistance of cotton batting: (a) start, (b) test in progress, and (c) end of the test. Cotton batting stack on left of (a) is placed on top of the cigarette/cotton batting stack on the right of (a) to form the testing setup in (b). 
In 2007, ASTM introduced a standard test for measuring the thermal penetration of BF for soft furnishings (ASTM D7140 [14]). The BF is exposed to a well-defined and controlled open flame heat source (with a heat flux of $46 \mathrm{~kW} / \mathrm{m}^{2}\left(1.1 \mathrm{cal} / \mathrm{cm}^{2} / \mathrm{s}\right.$ )) for $60 \mathrm{~s}$ (Figure 3). Such a flaming heat source is known to provide a $30 \%$ radiant heat and $70 \%$ convective heat flux [17]. This test method essentially measures the heat penetration through a BF when exposed to an open flame and determines whether the heat transfer through the BF is sufficient to ignite underlying materials. This approach is used for quality control assessment and screening of BFs measures the thermal penetration upon exposure to an open flame heat source. The standard, however, does not define a heat transfer threshold for textile materials that can be used as a criterion for fire barrier materials.

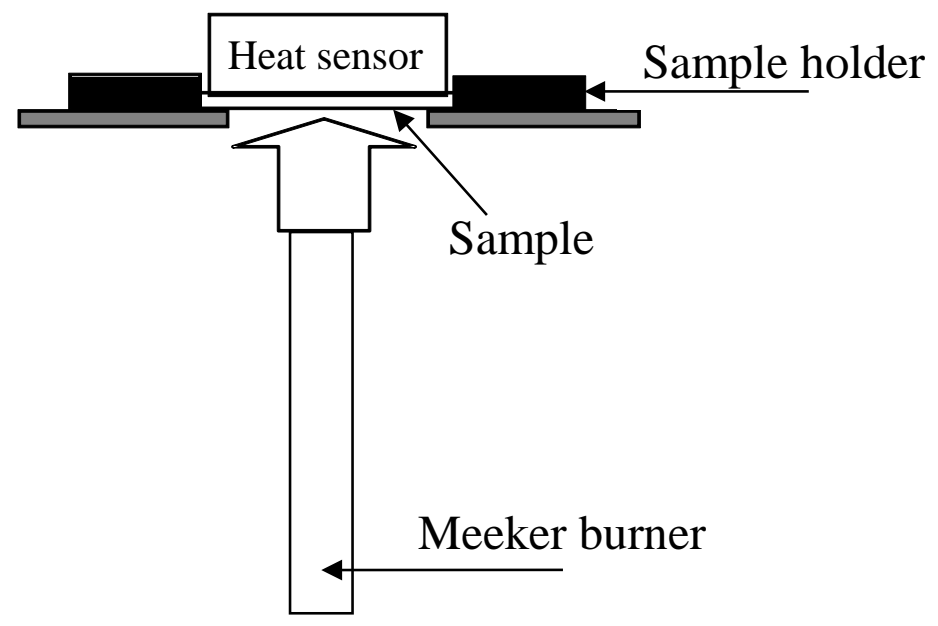

Figure 3. Schematic of ASTM D 7140 test method for BFs.

The California Bureau of Home Furnishings and Thermal Insulation (BHFTI) has no specific test for a BF component. The smoldering ignition test for upholstered furniture described in Cal TB 116 [13] does not mention the use of a BF, but it does require the finished product or the prototype mockup to be tested with the actual components of the product sold, which may include, at the discretion of the manufacturer, a BF. The current Cal TB 117 [12] test method measure the tendency of the barrier material to smolder after exposure to a smoldering cigarette over a smolder prone cover fabric. A 2002 revision of TB 117 considered incorporating a test method specifically for highloft BFs (characterized by low area density, high thickness, and a greater volume of air than fiber) utilizing open flame ignition tests in both vertical and horizontal orientations. For the vertical orientation, the flame application time was $10 \mathrm{~min}$ with a flame length of $102 \mathrm{~mm}$ (4.0 in), and for horizontal testing a gas flame with an energy output of $57.6 \mathrm{~kJ} / \mathrm{s}$ was used. To pass this open flame ignition test, the highloft BF was required to selfextinguish by the end of the 10 min test time, and the mass loss allowed was limited to $4 \%$ of the initial mass [11]. This test method was modified for BFs used in mattresses and was quickly adopted by the mattress industry as a quality assurance test for BFs [15], particularly cotton battings. The modified fire barrier test for mattress application uses a larger test specimen 
(30.48 cm x $30.48 \mathrm{~cm}$ (12 in x 12 in)) and a flaming ignition source that simulates the 16 CFR 1633 burner with a gas flow rate of $350 \mathrm{ml} / \mathrm{min}$. The flame is applied for a duration of $70 \mathrm{~s}$. The specimen is tested in vertical as well as horizontal orientations (Figure 4). The temperature on the opposite side of the specimen is recorded using an infrared (IR) instrument. One of the most important observations during and after the test is a visual grading of the char formation. This test is material specific (exclusively for battings with at least $70 \%$ cotton) and hence has a limited application. BFs with constructions other than nonwoven battings e.g., thermally thin BFs, may not withstand this severe test. The latest proposed TB 117 [12], however, primarily contains a cigarette smoldering test and has no provisions for an open flame test of the furniture or its components [16].

The ASTM, UFAC, and BHFTI tests described above are commonly used by industry in the development and quality control assessment of BFs. For non-woven, highloft battings, quality control measures generally include weight, thickness, uniformity, and a burn test as described in the 2002 revision draft of TB 117. The burn tests are qualitative, with specific guidelines for assessing fire performance of BFs. Since BFs are generally expected to be self-extinguishing, common flammability test methods for such materials include measurements of the time of afterflame and afterglow and the extent of fire damage in terms of char length, hole size, and weakened sample strength or embrittlement. The composite and component tests for BFs, described above do not quantify the fire performance of BFs.

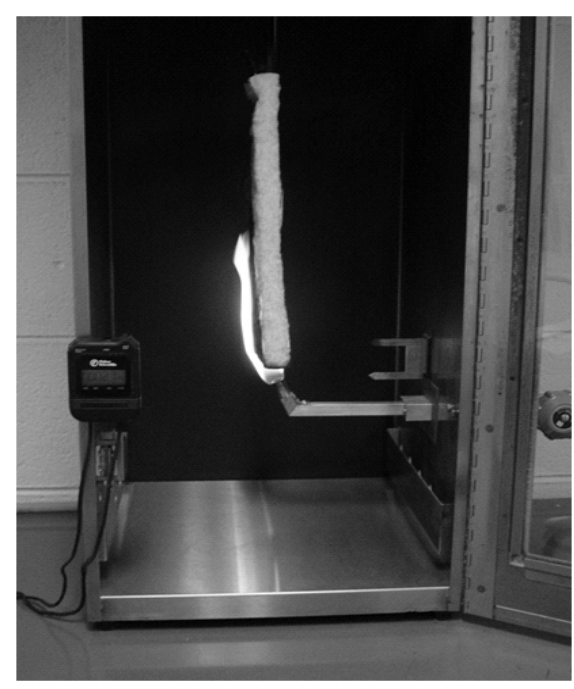

(a)

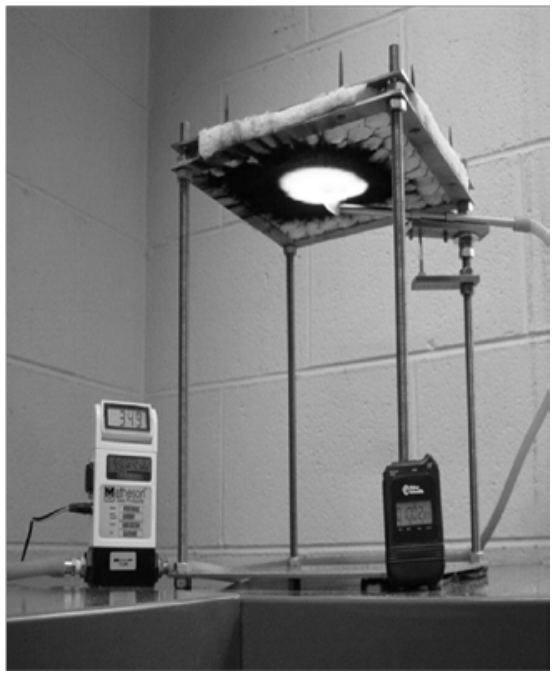

(b)

Figure 4. Modified Cal TB 117 for testing barrier flammability: (a) vertical and (b) horizontal configuration.

\section{The Rationale}

The purpose of this document is to provide the basis for guidelines to evaluate the performance of fire blocking BFs in soft furnishings. Fundamental BF properties that influence the heat transfer properties (HTP), as it relates to thermal protection of cushioning components in upholstered products are discussed. 
In this work, heat transfer characteristics of BFs exposed to combined radiant and convective heat flux are studied and reported for the first time. Similar studies by Shalev and Barker [17, 18] on heat transfer characteristics of protective clothing have been previously reported wherein heat transfer measurements were utilized to estimate the amount of time required to cause second degree burns on human skin. The focus on burn injury led to the use of a thermal protective performance (TPP) parameter, defined as the product of the incident flux and the time required for sufficient heat transfer through the material to induce a second degree burn on human skin generally estimated using a correlation provided by Stoll and Chianta [19].

A thermal protective performance (TPP) instrument developed by Measurement Technology Northwest was used, for the first time, to quantify the heat transfer characteristics of BFs. Earlier, such an instrument was used for characterizing the fire resistance of fabrics to investigate preventing or limiting burns to human skin. In such tests, a test fabric is exposed to a heat source, and the amount of heat transferred through the material is measured. Shalev and Barker [17, 18] have provided an excellent discussion of such tests for use with fabrics.

There are clear similarities between the use of fabrics to protect human skin from high temperature sources and the use of BF to protect soft fillings in upholstered furniture from an external fire. However, in the case of upholstered furniture the goal is to prevent or limit the contribution of the filling material to the overall heat release rate of the fire. In practice, this requires limiting the amount of the filling material pyrolyzed to generate the potential fuel and/or limiting the burning of released pyrolyzate. Pyrolysis of organic materials is generally an endothermic process requiring the addition of heat. Thus the ability of a BF to reduce heat transfer to the filling is an important consideration. This suggests that one measure of the effectiveness of a BF is the amount of heat transferred through the material. In this work, a parameter based on the amount of heat transferred through a barrier during a $70 \mathrm{~s}$ application of a heat source is proposed as a suitable parameter.

Since the focus of this work is to quantify thermal protection provided by a BF, we modified the NFPA 1971 [20] test method such that the specimen is exposed to a specified heat flux, for a given amount of time. Instead of TPP values, the results of the test were reported in terms of the heat flux passing through the material. The heat flux passing through the specimen is measured using a slug calorimeter. Low heat flux values imply good insulation properties, which help prevent heat and flames being transferred to the underlying cushioning. The test method is applicable to woven materials, knit materials, battings and nonwoven materials.

Flammability test methods that characterize ignitability, and heat release rate, properties of BFs are also discussed. Cone calorimeter experiments were performed to distinguish between BFs with respect to ignition times, peak heat release rate (PHRR), total heat released (THR), and char yield. The time to ignition (TTI) relates to how quickly a BF can ignite if the ticking or cover fabric catches fire. The PHRR is related to the 
maximum heat released by the burning $\mathrm{BF}$ that maintains the fire due to a positive feedback mechanism involved in the burning process while the THR reflects the total amount of flammable content of the specimen. The fire growth rate (FIGRA) index calculated by dividing the peak heat release by time to peak heat release (FIGRA = PHRR/TTP), can be used to estimate the predicted fire spread rate [30]. The higher the FIGRA index value, the higher the fire hazard. The char yield, both qualitative and quantitative, reflects the thermal protective property of the BF after it has been consumed in the fire. Thus, important information with regards to evaluating BFs can be obtained from cone calorimetry data.

A new bench-scale composite test method is also described to assess qualitative performance of BFs. Bench-scale laboratory tests for individual components are suitable for screening new materials. However, these component tests cannot characterize the fire hazard posed by upholstered composites, and, hence, composite flammability tests are essential to measure the fire performance under end-use conditions. Moreover, the flammability of upholstered products can be drastically impacted by the structure of BFs and of the finished product, and other factors, which may mean that it is not possible to predict the full-scale behavior of the BFs without testing them in the context that defines the final product. In addition, BFs could fail due to stress-induced separation/splitting that results in exposing the cushioning materials of the soft furnishing to high temperatures and flames. When exposed to heat and/or flames, BFs undergo chemical and/or physical changes (e.g., dissipation of heat, release of FR, and formation of a protective char), and these may cause the BF to shrink, become stiff and/or brittle, and/or become thinner. In an attempt to better understand the burning behavior of composite assemblies and for assessing fire performance of barrier materials a bench-scale composite test has been developed. Finally, general principles for engineering and evaluating the effectiveness of BFs are provided.

\section{Materials ${ }^{1}$}

The types of BFs used in soft furnishings are mainly influenced by end user applications and cost. Most commonly, highloft, nonwoven fiber battings are used in residential mattress applications, whereas coated or laminated textiles are more common in institutional and residential upholstered furnishing applications [4]. BFs constructed from inherently fire resistant fibers $^{2}$ are frequently used in high-performance applications (e.g., aircraft seating, seating in other mass transport vehicles and public buildings). The range is indicated by list of commercially available BFs included in this study given in Table 2. The list includes a variety of textile structures including highloft, nonwoven battings, knitted, and woven structures used in a variety of applications. With such a varied selection of BFs, it was possible to identify the

\footnotetext{
${ }^{1}$ Certain commercial equipment, instruments or materials are identified in this paper in order to specify the experimental procedure adequately. Such identification is not intended to imply recommendation or endorsement by the National Institute of Standards and Technology, nor is it intended to imply that the materials or equipment identified are necessarily the best available for this purpose.

${ }^{2}$ Fire resistant fibers self-extinguish upon removal of the ignition source, thus preventing flame spread, whereas flame retarded fibers burn slowly due to a flame retarding mechanism.
} 
factors to which the heat transfer properties were related most significantly. The BFs varied in average thicknesses from $0.1 \mathrm{~mm}$ to $7.8 \mathrm{~mm}$. The thickness of BFs was determined using a Check-line Digital Thickness Gauge (model 500-JD-A). This device uses the principal of capacitance and the circuits are designed to measure changes in capacitance with changes in the thickness of BF. The change in voltage due to change in capacitance is converted to a unit of distance. Since it is known that surface fibers play a significant role in the effective thermal thickness of the fabrics [21], the thickness of BFs was determined at a low measuring force of $0.6 \mathrm{~N} \pm 0.3 \mathrm{~N}$ per unit area. In order to obtain consistent and more accurate thickness measurements of textile materials, a precision spring system [22] was used.

The experimental matrix covers the most extensively used fibers and fiber blends in the BF industry [4]. These include boric acid treated cotton, flame retardant (FR) rayon, FR polyester, glass fiber, carbon fiber and blends thereof. The exact fiber blend composition are proprietary and thus were not available. BFs made from the latest core-yarn technology and highperforming carbon fibers (oxidized polyacrylonitrile fibers) were included.

Depending on the mode of fire blocking technology employed, the BFs in Table 2 are identified as active or passive. Active BFs have a chemical effect on the fire. The chemical activity of active BFs can be in the condensed phase through enhanced char formation (e.g., BF-1, BF-2, BF-3, BF-4, BF-5), gas phase via flame quenching and/or intumescence (e.g., BF-10, BF-11, BF12, BF-15), or both. For the purpose of this report, only the BFs that can extinguish the flames and prevent the outer upholstery from burning are classified as active BFs in Table 2. Passive fire barriers (BF-1, BF-2, BF-3, BF-4, BF-5, BF-6, BF-7, BF-8, BF-9, BF-13, BF-14, BF-16, BF-17, BF-18, BF-19) prevent or delay the ignition of interior cushioning materials; however, they do not prevent burning of the outer upholstery. Their effectiveness derives from serving as a physical and/or thermal barrier between some or all of the fuel and the potential ignition source.

BFs can also be distinguished as thermally thick or thermally thin materials. A material is considered to be thermally thick if the heat penetration depth is less than the physical depth [23]. In thermally thin materials, heat absorbed on one surface of the material penetrates its thickness sufficiently rapidly, so there is no significant temperature gradient through the material's depth [24]. 
Table 2. Description of BFs used in soft furnishings. Uncertainties are reported as Type A uncertainties with experimental standard deviations.

\begin{tabular}{|c|c|c|c|c|c|}
\hline Sample & Fiber blend & Structure & Area density ${ }^{\S}, \mathrm{g} / \mathrm{m}^{2}$ & Average thickness, mm & Type of BF \\
\hline BF-1 & FR rayon/polyester & $\begin{array}{c}\text { Thermally bonded } \\
\text { Highloft }\end{array}$ & 155 & $4.1 \pm 0.1$ & Passive \\
\hline $\mathrm{BF}-2$ & FR rayon/polyester & $\begin{array}{c}\text { Thermally bonded } \\
\text { Highloft }\end{array}$ & 230 & $6.7 \pm 0.2$ & Passive \\
\hline $\mathrm{BF}-3$ & FR rayon/polyester & Needle punched & 240 & $7.8 \pm 0.6$ & Passive \\
\hline $\mathrm{BF}-4$ & $\begin{array}{l}\text { Boric acid treated cotton/ FR } \\
\text { rayon/polyester }\end{array}$ & $\begin{array}{l}\text { Needle punched } \\
\text { /Stratified }\end{array}$ & 230 & $5.7 \pm 0.1$ & Passive \\
\hline BF-5 & Boric acid treated cotton & Needle punched & 230 & $6.9 \pm 0.8$ & Passive \\
\hline BF-6 & Carbon fiber & Nonwoven felt & 500 & $3.9 \pm 0.2$ & Passive \\
\hline BF-7 & Carbon fiber & Nonwoven felt & 576 & $7.2 \pm 0.1$ & Passive \\
\hline BF-8 & FR rayon/polyester & Needlepunched & 237 & $4.3 \pm 0.1$ & Passive \\
\hline BF-9 & FR rayon/polyester & Needlepunched & 240 & $2.2 \pm 0.1$ & Passive \\
\hline BF-10 & FR polyester /FR rayon & Stitchbond & 165 & $0.7 \pm 0.1$ & Active \\
\hline BF-11 & $\begin{array}{c}\text { Glass fiber core/ FR acrylic } \\
\text { fiber }\end{array}$ & $\begin{array}{l}\text { Knit Barrier using } \\
\text { core yarn technology }\end{array}$ & 186 & $0.9 \pm 0.1$ & Active \\
\hline $\mathrm{BF}-12$ & $\begin{array}{c}\text { Glass fiber core/ FR acrylic } \\
\text { fiber }\end{array}$ & Knit Barrier & 237 & $1.6 \pm 0.1$ & Active \\
\hline $\mathrm{BF}-13$ & $\begin{array}{l}\text { FR rayon/glass fiber/ poly } \\
\text { lactic acid (PLA) fiber }\end{array}$ & Knit Barrier & 165 & $1.4 \pm 0.1$ & Passive \\
\hline BF-14 & Carbon fiber & Circular knit & 250 & $1.2 \pm 0.1$ & Passive \\
\hline $\mathrm{BF}-15$ & $\begin{array}{c}\text { Glass fiber core/ FR acrylic } \\
\text { fiber }\end{array}$ & Woven Barrier & 170 & $0.5 \pm 0.1$ & Active \\
\hline $\mathrm{BF}-16$ & $\begin{array}{c}\text { FR rayon/crystalline silica } \\
\text { fiber/poly lactic acid (PLA) } \\
\text { fiber }\end{array}$ & Nonwoven & 290 & $2.9 \pm 0.1$ & Passive \\
\hline $\mathrm{BF}-17$ & Glass fiber & Woven Barrier & 150 & $0.2 \pm 0.1$ & Passive \\
\hline BF-18 & Glass fiber & Woven Barrier & 170 & $0.1 \pm 0.1$ & Passive \\
\hline BF-19 & Glass fiber & Woven Barrier & 320 & $0.3 \pm 0.1$ & Passive \\
\hline
\end{tabular}

$\S$ For textile materials, density is generally expressed as mass per unit area. The standard uncertainty (Type B) in measuring area density is about $\pm 5 \mathrm{~g} / \mathrm{m}^{2}$. 


\section{Test Methods}

\subsection{Heat transfer}

A schematic of the TPP test apparatus is shown in Figure 5. It consists of two propane fueled Meeker burners and a bank of nine quartz radiant heating elements calibrated to provide $50 \%$ convective and $50 \%$ radiative heat flux. This heat source differs from the one used in ASTM D7140 described earlier in that the ratio of radiant to convective heat fluxes is different. However, studies [17] have shown that the heat transfer through test material is insensitive to changes in the radiant/convective ratio.

The Meeker burners were tilted at an angle of $45^{\circ}$ from the horizontal (Figure 5) so that the flames converged at a point immediately under the test specimen. The propane burner flames were visually monitored to avoid any turbulence. The specimens were exposed to a total heat flux of $65 \mathrm{~kW} / \mathrm{m}^{2} \pm 5 \mathrm{~kW} / \mathrm{m}^{2}$ for $70 \mathrm{~s}$. This exposure condition represents the maximum heat flux that a mattress top experiences during a full-scale open flame test $[25,26]$ as described in 16 CFR part 1633 [27]. The total heat flux was calibrated every day prior to experimentation.

The sample carriage consists of a frame for securing the BF specimen and a heat sensor placed in direct contact with the back of the BF. The heat sensor is a slug calorimeter embedded in an insulating board which is placed face down on the fabric assembly. The slug calorimeter consists of a blackened copper disc $40 \mathrm{~mm}$ in diameter with a thickness of $1.6 \mathrm{~mm}$. Three 32gauge chromel/alumel thermocouples are mounted in the disk at $120^{\circ}$ intervals. The heat flux sensor with calibrated slug calorimeter is connected to a data acquisition system which records the rise in temperature of the sensors as a function of time. Thermocouples secured in the copper slug calorimeter, which is in direct contact with the back surface of the specimen, measure the rise in temperature. The rates of temperature rise or the slope of the temperature versus time trace are used in conjunction with the calorimeter constants provided by the manufacturer to compute the heat flux received. The water-cooled shutter is pneumatically actuated and automated for precise control of exposure timing. It covers the heating elements to allow time for the sample carriage to move into position above the heat source. At the start of the test, the heat sensors are approximately at room temperature. The rise in temperature after exposure is calculated by subtracting the starting temperature from the recorded temperature. The ThermDac software generates data in terms of time to second degree burn on human skin and a thermal protective performance (TPP) rating. The TPP rating of the test specimen is determined by multiplying the recorded protection time by the heat flux exposure and has units of energy per unit area $\left(\mathrm{cal} / \mathrm{cm}^{2}\right)$. The higher the TPP rating, the better the thermal protective performance of the fabric assembly. A particularly useful feature of this test procedure is a continuous calorimetric trace useful for analyzing the fabric heat transfer characteristics. 


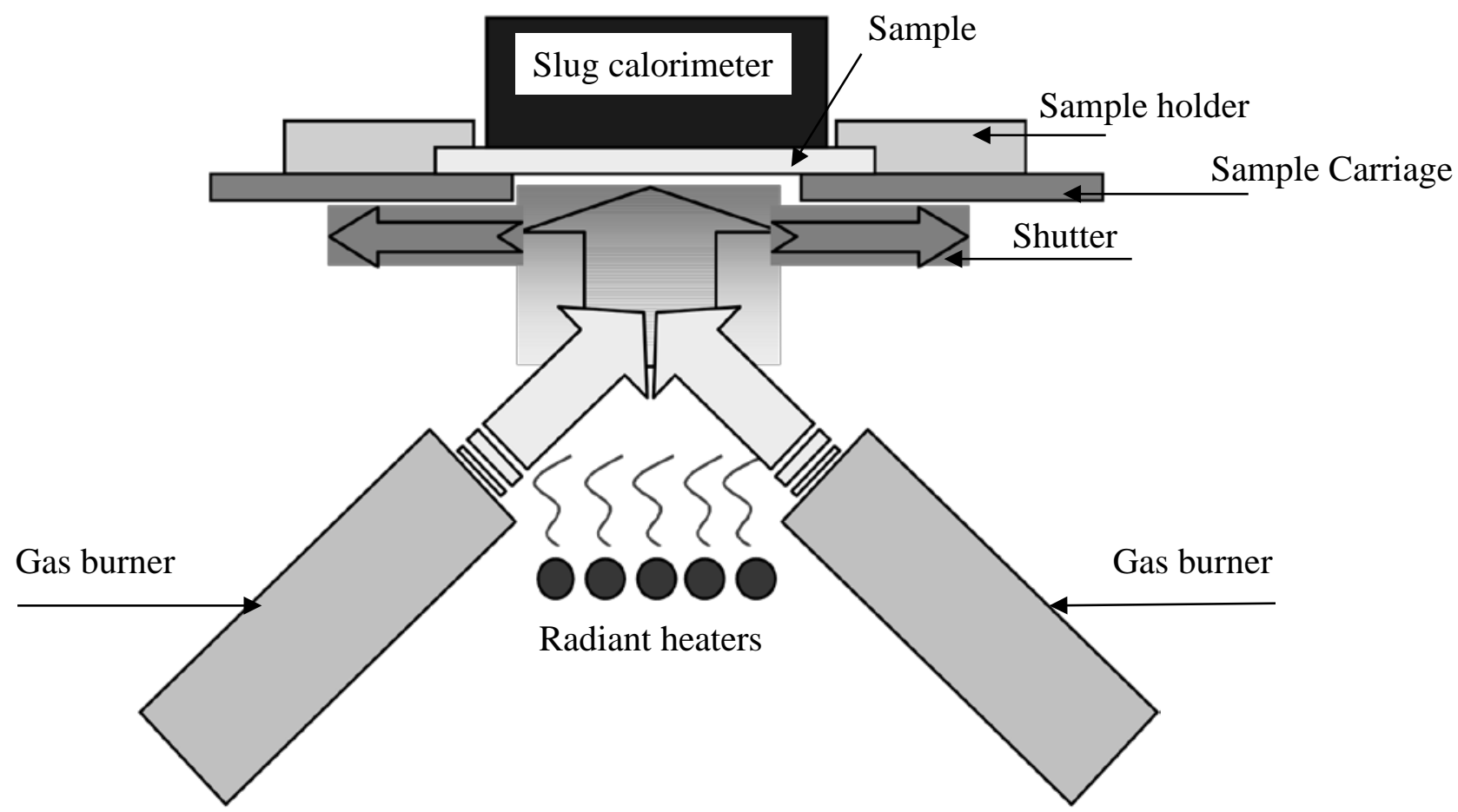

Figure 5. Schematic of TPP testing device.

BF materials were placed on the sample holder in the same configuration used in full-scale open flame flammability testing of a residential mattress, in that the ticking (fabric over the BF) is exposed to the heating elements and the $\mathrm{BF}$ is in contact with the sensor. This condition measures the protective characteristics of the total assembly. The ticking material used in this study was a stitchbond fabric containing 69 \% rayon and 31 \% FR polyester blend, and was kept consistent in all composite specimens. Such a ticking material was chosen to avoid any meltdripping of ticking and/or BFs, thereby damaging the quartz tubes. The use of a FR ticking, however, is not expected to interfere with measurements of the heat transfer properties of BFs.

Upon completion of the test, the slug calorimeter was carefully examined for any sticky residue or char from the degraded BF. Although prior studies have shown that the state of the copper surface has little influence on the measurement of heat transfer through textile materials [28], any accumulated residue was carefully cleaned from the sensor and sample holder surfaces.

\subsection{Cone calorimetry}

The cone calorimeter was operated according to the procedures provided in ISO 5660-1 [29]. The sample was located $2.5 \mathrm{~cm}$ below the base of the cone. Most textile materials are thermally thin materials and have very high air-to-fiber ratio. This characteristic feature of textile materials makes it very difficult to maintain their configuration. Such materials often curl, melt, and char when exposed to high incident heat fluxes. The changing specimen configuration complicates interpretation of the experimental results. In order to limit configuration changes in materials 
and improve measurement reproducibility, the specimen assembly [30] shown in Figure 6 was used. Fine wires passing over the top of the fabric provided additional stability. Pieces of ceramic blanket of various thicknesses were utilized to ensure that barriers were located at the proper height below the cone calorimeter.

An incident heat flux of $50 \mathrm{~kW} / \mathrm{m}^{2}$ was judiciously selected, (1) because it represents a developing fire more than a fully developed fire at $65 \mathrm{~kW} / \mathrm{m}^{2}$ [31], (2), this flux represents the immediate reaction-to-fire when the $\mathrm{BF}$ is exposed to the burners in a full-scale mattress flammability test described in 16 CFR part 1633 [1], and (3), because the BFs are expected to be fire resistant and /or flame resistant materials, ignition of such materials at incident heat fluxes below $50 \mathrm{~kW} / \mathrm{m}^{2}$ were not expected.

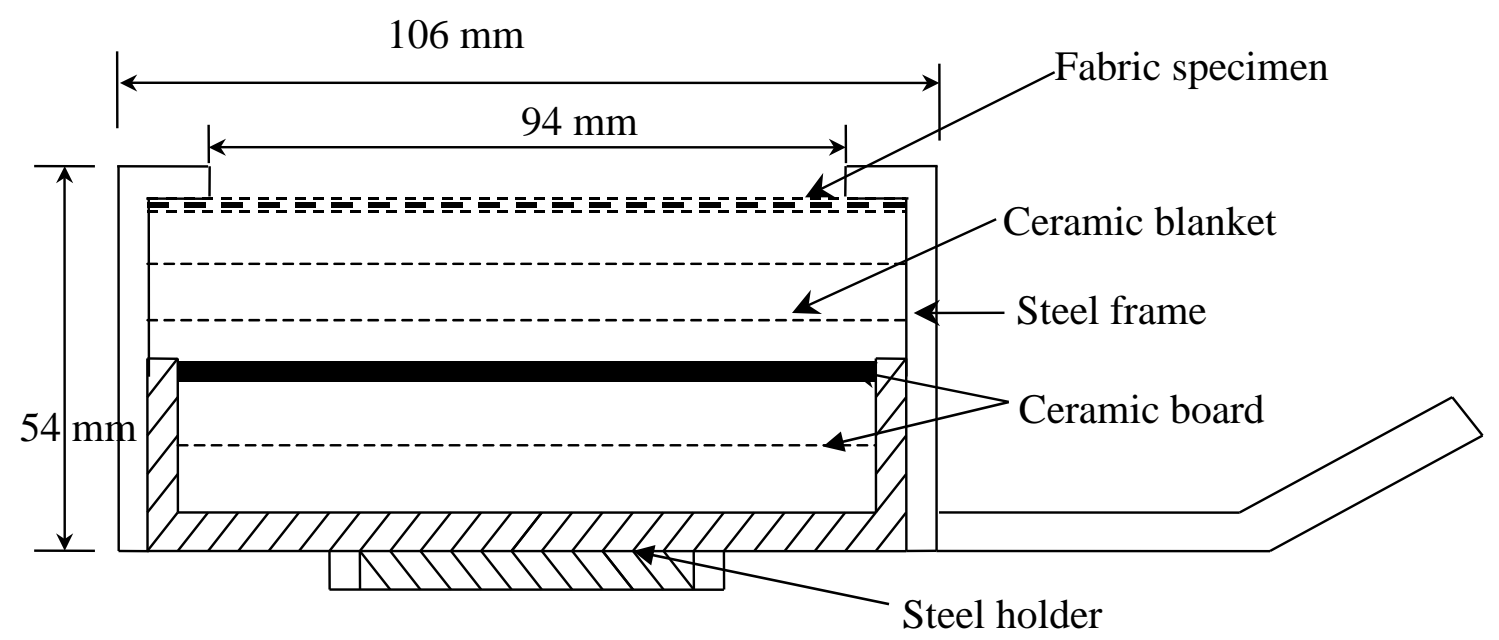

Figure 6. Specimen assembly for cone calorimetry experiments.

\subsection{Composite test}

A modified "Mydrin test" [32] was chosen as the bench-scale test for the BFs. The Mydrin test was originally developed [33] as a simplified version of a Source 1 ignition condition in British Standard BS5852: 1979 [34]. Its purpose was to assess the flammability performance of FR cover fabrics used in upholstered furnishings. The test was considered to be an acceptable mockup test that inexpensively and accurately indicate the ignition behavior of full-scale products of complex structures when tested in accordance with BS5852 [32]. The test set-up is shown in Figure 7. A premixed butane gas burner was used with a flame height adjusted to $40 \mathrm{~mm}$ as specified in BS 5438 [35]. The flame was applied to the face of the composite for $20 \mathrm{~s}$ and then removed. If the composite continued to flame and/or smoke for more than 2 mins and/or, heat or afterglow for more than 15 min after removal of the ignition source, a "fail" was recorded for the test, otherwise a "pass" was reported. This test criterion, however, was limited to mock-up composites using FR cover fabrics. Since BFs were used in this study, the Mydrin test was modified as described below. 


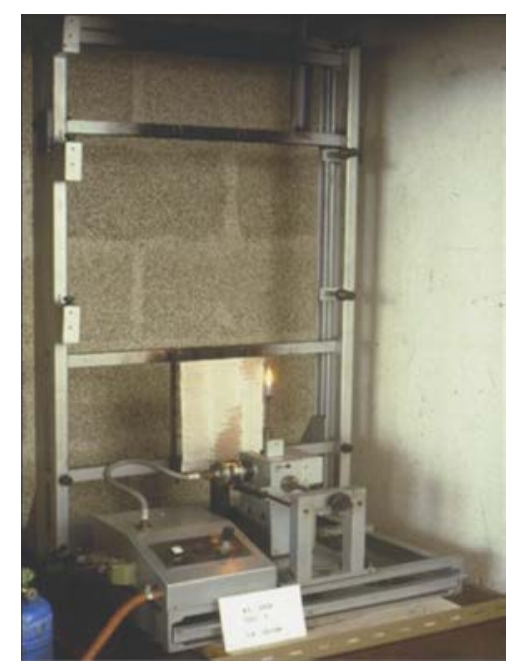

Figure 7. Vertical flammability test rig developed for the 'Mydrin' test.

The new bench-scale composite test developed for this study included a new specimen configuration including a piece of PUF (average density of $28.4 \mathrm{~kg} / \mathrm{m}^{3}$ or $1.77 \mathrm{lb} / \mathrm{ft}^{3}$, and average air permeability of $0.33 \mathrm{~m}^{3} / \mathrm{min}$ or $11.7 \mathrm{ft}^{3} / \mathrm{min}$ ) of approximately $220 \mathrm{~mm}$ x $150 \mathrm{~mm}$ x $22 \mathrm{~mm}$ dimensions as the flammable filling part of the composite to be tested. PUF samples were custom made according to NIST specifications in a small pilot plant by Foamex International Inc., PA (FXI). Manufacturing details and physical properties of PUF (formulation B12) are described in a previous report [36]. The BFs and the ticking were cut into pieces, approximately $264 \mathrm{~mm} \times 194 \mathrm{~mm}$ and pinned onto the foam to form an upholstered composite. The BF was placed between the ticking and the PUF. The back side of the foam was not covered with BF and the ticking. The fire blocking performance of BFs was tested with and without the ticking. The ticking selected for this composite test was a woven fabric with acrylic backcoating and had a flame spread rate of $37 \mathrm{~mm} / \mathrm{s} \pm 3 \mathrm{~mm} / \mathrm{s}$ in the vertical orientation when subjected to an open flame as defined in BS 5438 [35]. The ticking has an area density of approximately $200 \mathrm{~g} / \mathrm{m}^{2}$ with a fiber composition of $77 \%$ rayon and $23 \%$ polyester. This particular ticking is classified as Class B according to its smoldering performance as defined in 16 CFR part 1632.6 [37].

Initially, the composites were tested as an assembly of PUF/BF/Ticking. Composite samples which showed self-extinguishing properties in the presence of a fairly flammable ticking were not included in further testing. The PUF/BF/Ticking composite samples that burned extensively, primarily due to burning of ticking, were tested without tickings. Burning behavior was characterized in terms of duration of the flaming, thermal damage to the foam, and selfextinguishing behavior.

The composite bench-scale test employed for this study is still in the developmental stage. The test method has its limitations with respect to sample size, edge effects, and orientation of the sample. Furthermore, PUF as a filling material has long shown high variability in such type of composite tests and requires extensive replication in order to obtain satisfactory results. The reproducibility and repeatability of the test therefore needs to be studied further. 


\section{Results and Discussion}

\subsection{Heat transfer properties of BFs}

The heat transfer characteristics of BFs have been assessed using the modified NFPA 1971 test method described in Section 4.1. The TPP ratings for BFs derived from the ThermDac software are given in Table 3. TPP rating, as defined in the NFPA 1971, is the product of incident heat flux and recorded tolerance time for second degree burn on human skin [20]. Thus, the higher the TPP rating, the better is the insulation of the material. For firefighter's protective clothing, the NFPA 1971 requires TPP rating of $146 \mathrm{~J} / \mathrm{cm}^{2}\left(35 \mathrm{cal} / \mathrm{cm}^{2}\right)$. The TPP ratings for BFs range from as low as $38 \mathrm{~J} / \mathrm{cm}^{2}\left(9 \mathrm{cal} / \mathrm{cm}^{2}\right)$ for thermally thin BFs (BF-10, BF-11, and BF-15) to as high as $268 \mathrm{~J} / \mathrm{cm}^{2}\left(64 \mathrm{cal} / \mathrm{cm}^{2}\right)$ for thermally thick BF; primarily consisting of inorganic carbon fibers. A general trend of increasing TPP rating with BF thickness can be noted from Figure 8. BF-7 is an outlier in Figure 8 with its disproportionately high TPP rating compared to BF-2 and BF-5 with similar thicknesses of $7 \mathrm{~mm}$. BF-7 consists of inherently fire resistant carbon fibers that do not thermally decompose and the thickness of the BF-7 is maintained throughout the test as opposed to BF-2 and BF-5. The organic fibers in BF-2 and BF-5 thermally decompose, thereby reducing the thickness and TPP rating. No particular correlation was noted for TPP ratings and area density of BFs. Increasing area density may inhibit convective heat transfer, but may also enhance conductive heat transfer.

Since, TPP values are based on tolerance time for second degree burn on human skin and have limited applicability with regards to thermal protection of cushioning layers in an upholstered product, heat transfer characteristics of BFs were also assessed independently of the second degree burn criterion. The average rise in temperature, the heat flux recorded at the unexposed surface of a BF, the total amount of heat energy transferred (THT) through the BF, and the maximum heat flux measured at the unexposed side of a BF during a $70 \mathrm{~s}$ exposure time are given in Table 3. Figure 9 is a plot of THT versus TPP for various BFs. The results of a linear least square curve fit is shown as a straight line. The correlation coefficient for the fit was $\mathrm{R}^{2}=$ 0.63 which indicates a relatively weak correlation between the measures of heat transfer. The weak correlation is due to the differences in limiting criteria for calculating the two measures of heat transfer as described earlier.

The increases in temperature of the unexposed surface as a function of time for thermally thin woven and knitted BFs are shown in Figure 10. BF-10 (a stitchbond material) is also included in this category of woven barrier materials since the physical characteristics are similar to those of woven materials. BF-10, BF-11, BF-12, BF-13, and BF-15 show instantaneous rises in temperature as opposed to BF-14, BF-17, BF-18, and BF-19, where rises in temperature at the unexposed surface are not seen until almost $20 \mathrm{~s}$ of exposure to the heat flux. The latter BFs have very low gas permeability and therefore very little, or no, heat transfer via convection. Heat transfer in these BFs is primarily by conduction and radiation. Moreover, conductive heat transfer is negligible under highly turbulent flaming conditions [17], thereby resulting in delays in temperature rise. 


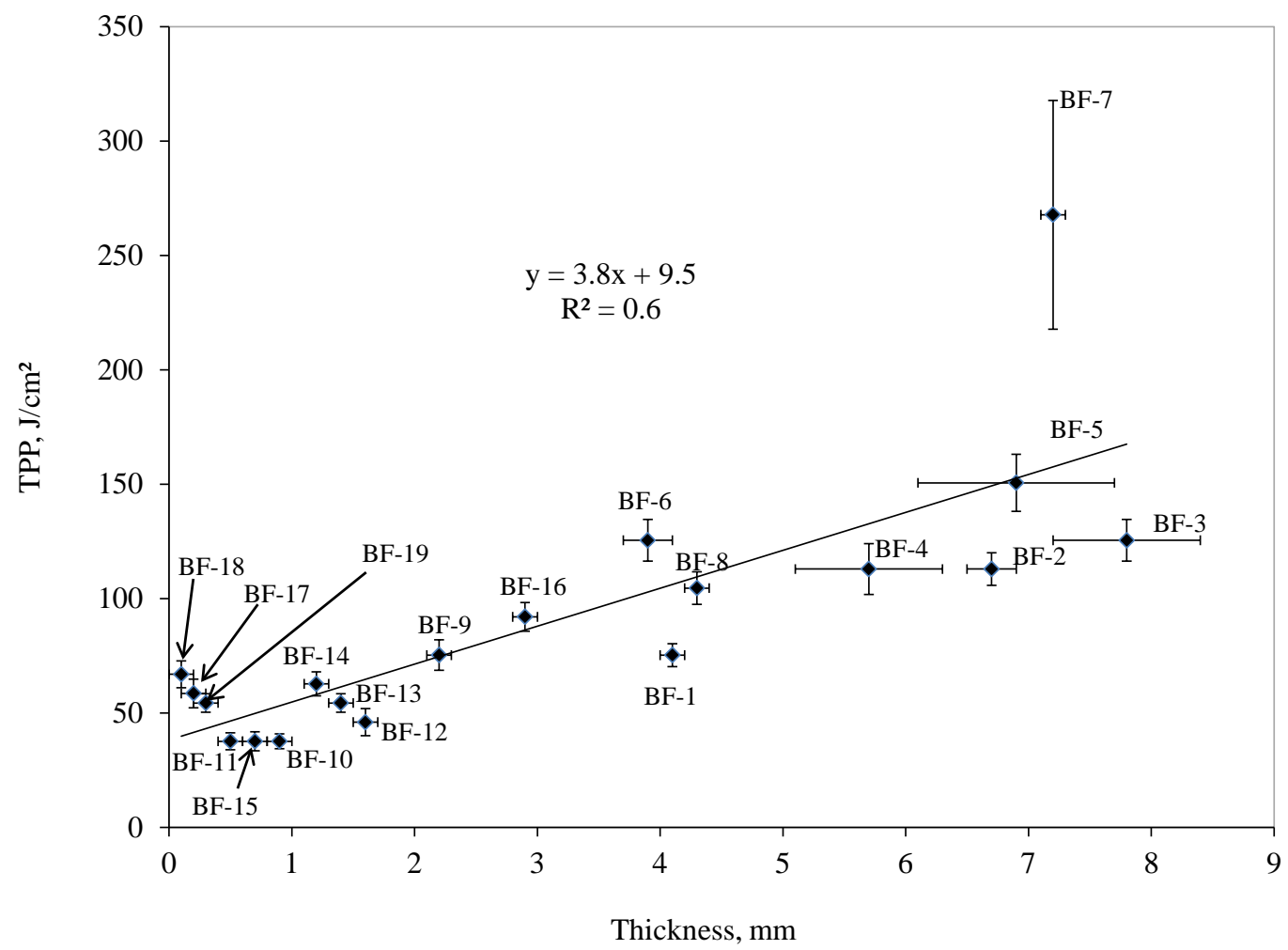

Figure 8. Correlation between TPP and thickness of BFs. Uncertainties are reported as Type A uncertainties with experimental standard deviations.

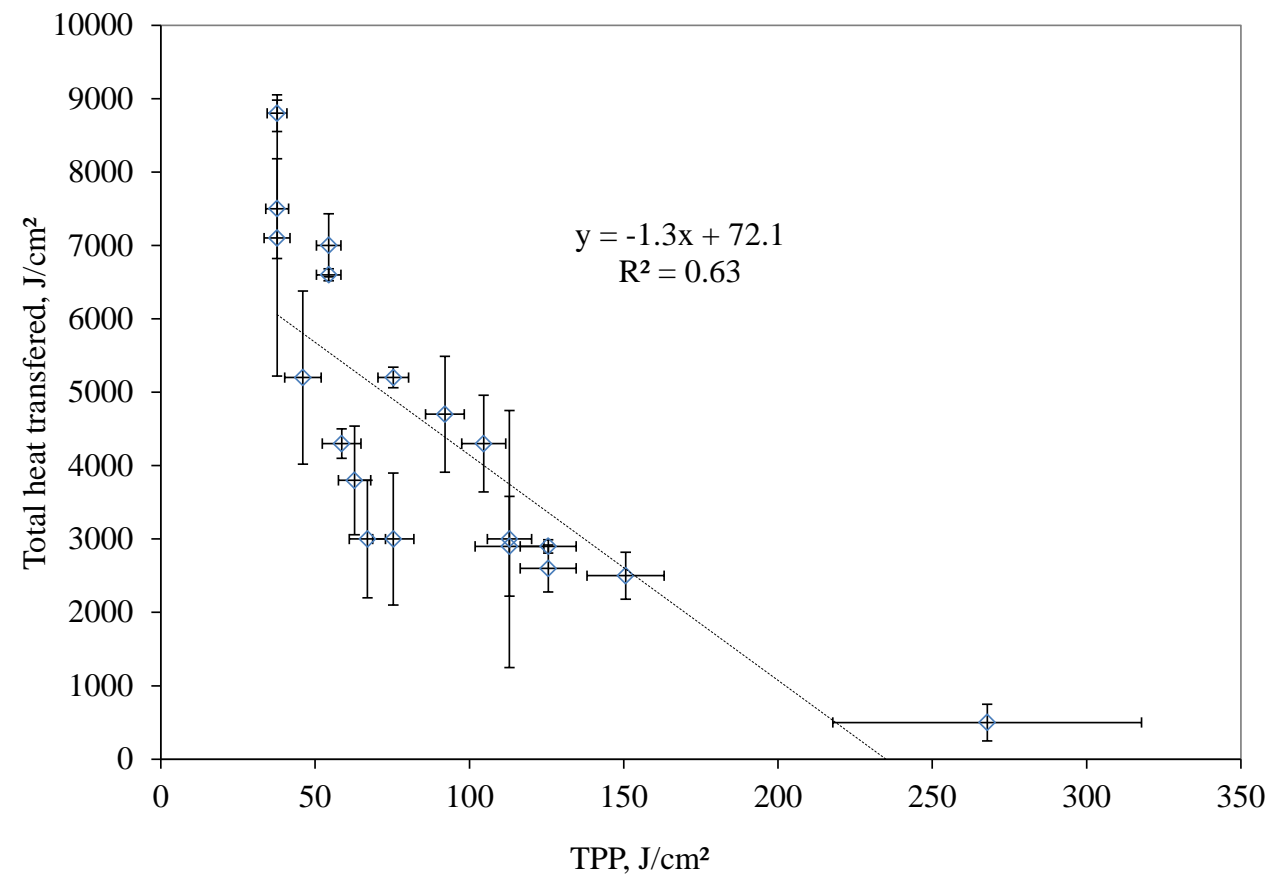

Figure 9. Correlation between THT and TPP ratings of BFs. Uncertainties are reported as Type A uncertainties with experimental standard deviations. 
Figure 11 shows temperature-time curves for nonwoven BFs. Generally, all nonwoven, highloft BFs show lower heat transfer as compared to thermally thin, woven and knitted BFs. Increase in temperature at the unexposed surfaces of thermally thick BFs are not seen until the BFs start decomposing. Thermally thin BFs show temperature rises up to $300^{\circ} \mathrm{C}$ during the $70 \mathrm{~s}$ exposure time, whereas maximum temperatures recorded at the unexposed surface of thermally thick BFs are all less than $225^{\circ} \mathrm{C}$. For some BFs, the initial slopes of the temperature-time curves vary because the heat exposure produces fundamental changes in fabric thermal and spatial properties through mechanisms of pyrolysis, char formation, and shrinkage. This is particularly true in the case of highloft nonwoven BFs where the volume of air is larger than the volume of fiber.

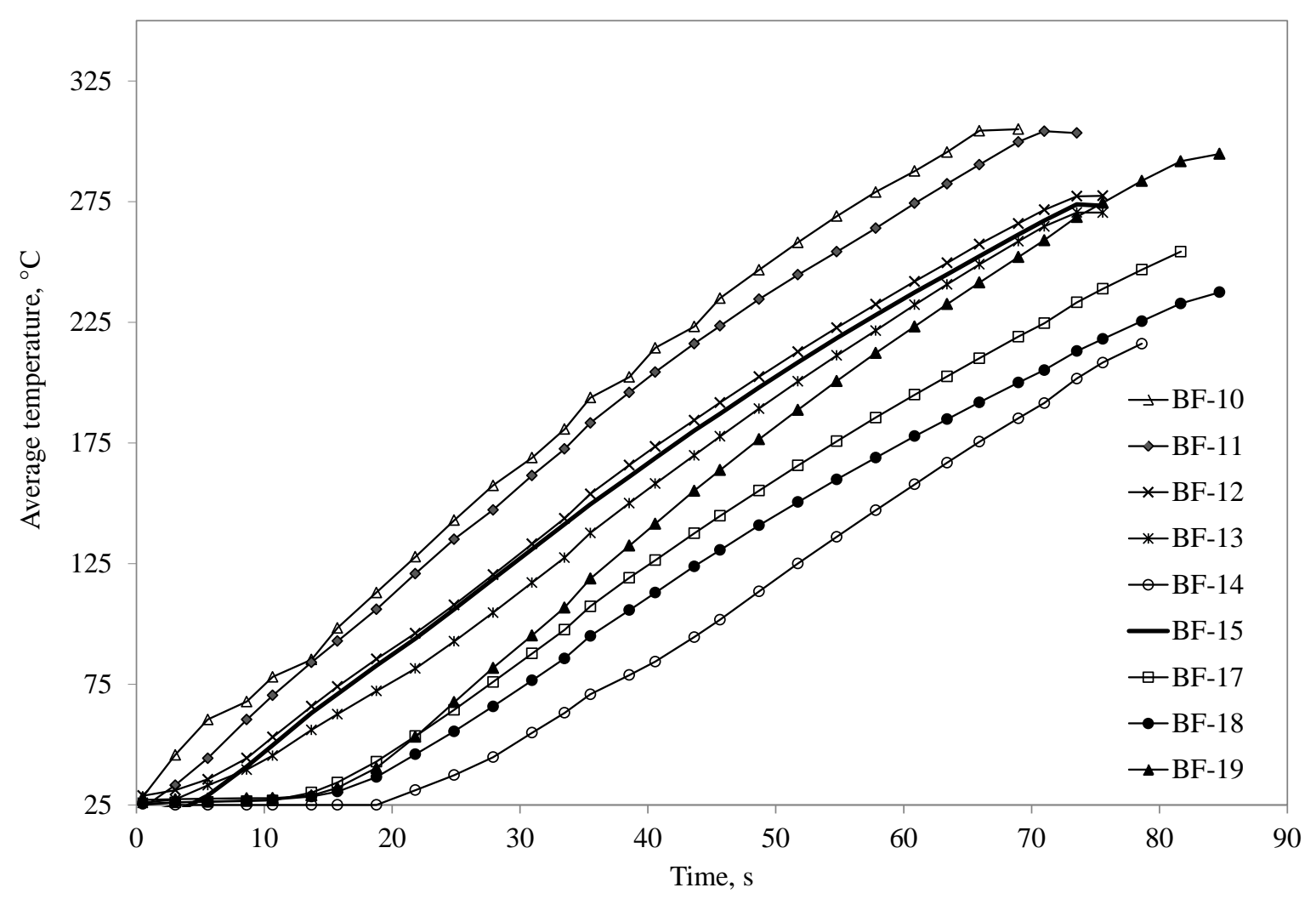

Figure 10. Thermal response of woven and knitted BFs. 


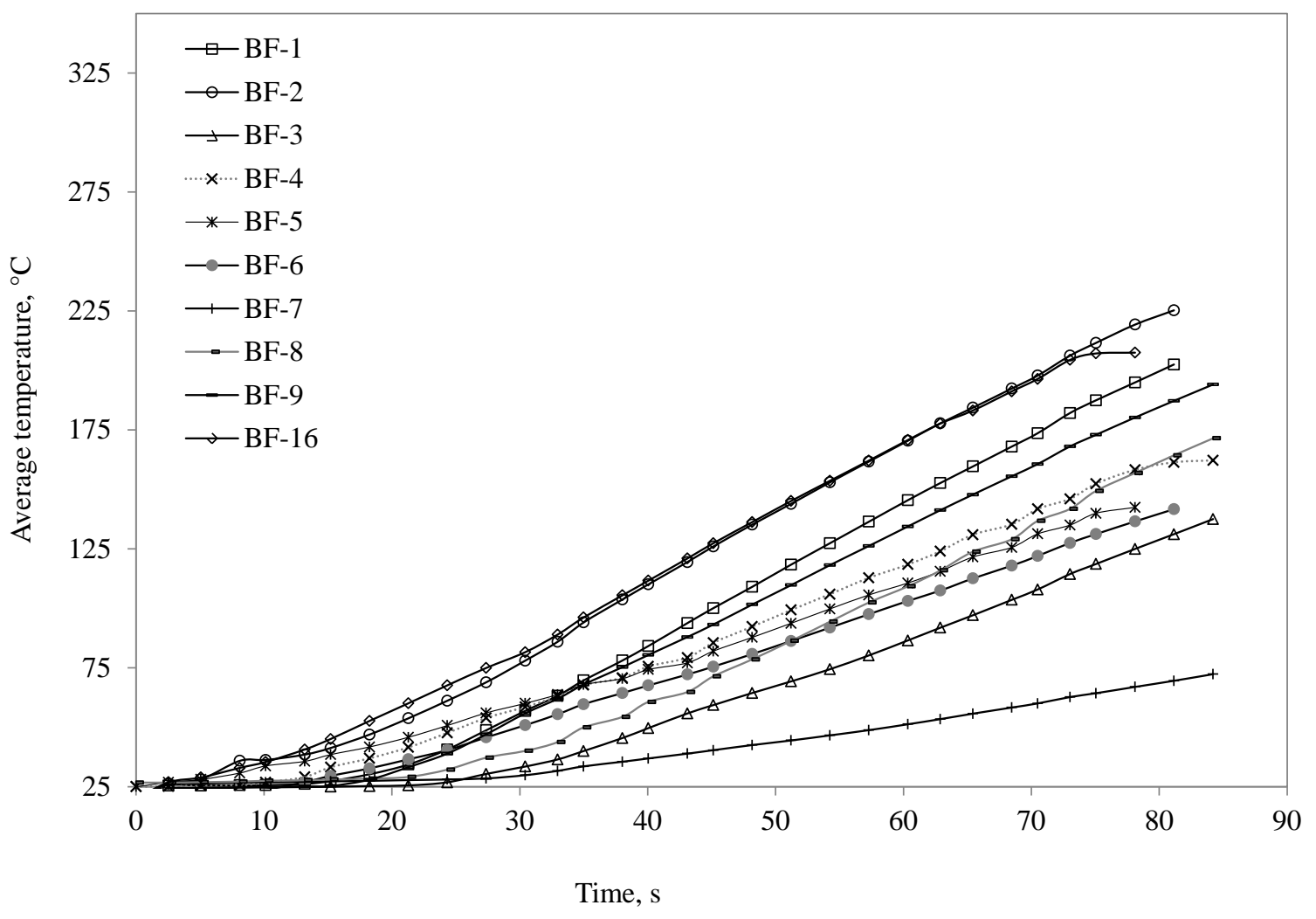

Figure 11. Thermal response of nonwoven BFs. 
Table 3. Heat transfer characteristics of BFs used in soft furnishings. Uncertainties are reported as Type A uncertainties with experimental standard deviations.

\begin{tabular}{|c|c|c|c|c|c|c|}
\hline $\begin{array}{c}\text { Sample } \\
\text { specification }\end{array}$ & $\begin{array}{l}\text { Average heating } \\
\text { rate of heat } \\
\text { sensors, }{ }^{\circ} \mathrm{C} / \mathrm{min}\end{array}$ & $\begin{array}{c}\text { Maximum heat flux } \\
\text { at unexposed side of } \\
\text { barrier at } 70 \mathrm{~s} \\
\mathrm{~kW} / \mathrm{m}^{2}\end{array}$ & $\begin{array}{c}\text { Total amount of } \\
\text { heat transferred, } \\
\mathrm{MJ} / \mathrm{m}^{2}\end{array}$ & $\begin{array}{c}\text { TPP,J/cm² } \\
\left(\mathrm{cal} / \mathrm{cm}^{2}\right)\end{array}$ & HTF, J/g & Description of char \\
\hline \multicolumn{7}{|c|}{ Thermally thick, non-woven, highloft BFs } \\
\hline BF-1 & $160 \pm 30$ & $13.1 \pm 0.4$ & $52.0 \pm 1.4$ & $75 \pm 4(18)$ & 335 & Very thin, fragile \\
\hline BF-2 & $150 \pm 18$ & $9.3 \pm 3.4$ & $30.2 \pm 17.5$ & $113 \pm 15(27)$ & 130 & Thick, pliable \\
\hline BF-3 & $115 \pm 5$ & $7.4 \pm 0.9$ & $28.5 \pm 0.9$ & $126 \pm 7(30)$ & 121 & Thick, flexible \\
\hline BF-4 & $120 \pm 5$ & $5.9 \pm 1.6$ & $28.8 \pm 6.8$ & $113 \pm 3(27)$ & 126 & $\begin{array}{l}\text { Thick, flexible char with no cracks or } \\
\text { holes }\end{array}$ \\
\hline BF-5 & $90 \pm 5$ & $5.2 \pm 1.6$ & $24.6 \pm 3.2$ & $151 \pm 14(36)$ & 109 & Several holes in the char \\
\hline BF-6 & $100 \pm 5$ & $7.3 \pm 0.4$ & $26.0 \pm 3.2$ & $126 \pm 8(30)$ & 52 & $\begin{array}{l}\text { Full thickness, flexible char with no } \\
\text { cracks or holes }\end{array}$ \\
\hline BF-7 & $50 \pm 5$ & $1.9 \pm 0.6$ & $4.6 \pm 2.5$ & $268 \pm 3(64)$ & 9 & $\begin{array}{l}\text { Full thickness, flexible char with no } \\
\text { cracks or holes }\end{array}$ \\
\hline BF-8 & $140 \pm 5$ & $9.10 \pm 0.3$ & $43.4 \pm 6.6$ & $105 \pm 3(25)$ & 181 & $\begin{array}{c}\text { Brittle char, little shrinkage and no } \\
\text { hole formation }\end{array}$ \\
\hline BF-9 & $150 \pm 5$ & $10.3 \pm 0.9$ & $30.4 \pm 9.0$ & $75 \pm 1(18)$ & 125 & $\begin{array}{l}\text { Brittle char, little shrinkage and no } \\
\text { hole formation }\end{array}$ \\
\hline BF-16 & $160 \pm 5$ & $11.0 \pm 1.2$ & $46.9 \pm 7.9$ & $92 \pm 3(22)$ & 162 & $\begin{array}{c}\text { Brittle char, little shrinkage and no } \\
\text { hole formation }\end{array}$ \\
\hline \multicolumn{7}{|c|}{ Thermally thin, woven and knitted BFs } \\
\hline BF-10 & $260 \pm 5$ & $16.0 \pm 4.9$ & $70.5 \pm 18.8$ & $38 \pm 1(9)$ & 430 & Thin, permeable char \\
\hline BF-11 & $250 \pm 5$ & $20.5 \pm 0.2$ & $87.5 \pm 2.5$ & $38 \pm 0.4(9)$ & 473 & Thin, flexible, permeable char \\
\hline BF-12 & $220 \pm 5$ & $11.5 \pm 5.8$ & $52.1 \pm 11.8$ & $46 \pm 1(11)$ & 219 & Thin, flexible, permeable char \\
\hline BF-13 & $220 \pm 5$ & $16.8 \pm 0.1$ & $66.0 \pm 0.8$ & $54 \pm 1(13)$ & 400 & Thin, flexible, permeable char \\
\hline BF-14 & $205 \pm 5$ & $12.9 \pm 0.9$ & $38.4 \pm 7.4$ & $63 \pm 2(15)$ & 152 & Thin, flexible, permeable char \\
\hline BF-15 & $230 \pm 5$ & $17.9 \pm 0.6$ & $75.4 \pm 6.8$ & $38 \pm 1(9)$ & 441 & Thin, permeable char \\
\hline BF-17 & $205 \pm 5$ & $10.9 \pm 1.7$ & $43.3 \pm 2.0$ & $59 \pm 2(14)$ & 287 & Thin, non-permeable char \\
\hline BF-18 & $190 \pm 5$ & $11.6 \pm 3.0$ & $30.0 \pm 8.0$ & $67 \pm 5(16)$ & 176 & Thin, non-permeable char \\
\hline BF-19 & $240 \pm 5$ & $16.7 \pm 1.9$ & $70.3 \pm 4.3$ & $54 \pm 2(13)$ & 219 & Thin, non-permeable char \\
\hline
\end{tabular}


Data were analyzed to determine the relationship between the heat transfer through BFs and BF characteristics such as fiber content, area density and thickness. Figure 12 shows a plot of THT through the BF as a function of the area density of BF and Figure 13 shows a plot of THT as a function of BF thickness. There is considerable scatter of data in the range of $150 \mathrm{~g} / \mathrm{m}^{2}$ to 300 $\mathrm{g} / \mathrm{m}^{2}$ in Figure 12, suggesting significant influence of fiber content. However, total heat transferred through the BF was approximately inversely related to its thickness (Figure 13).

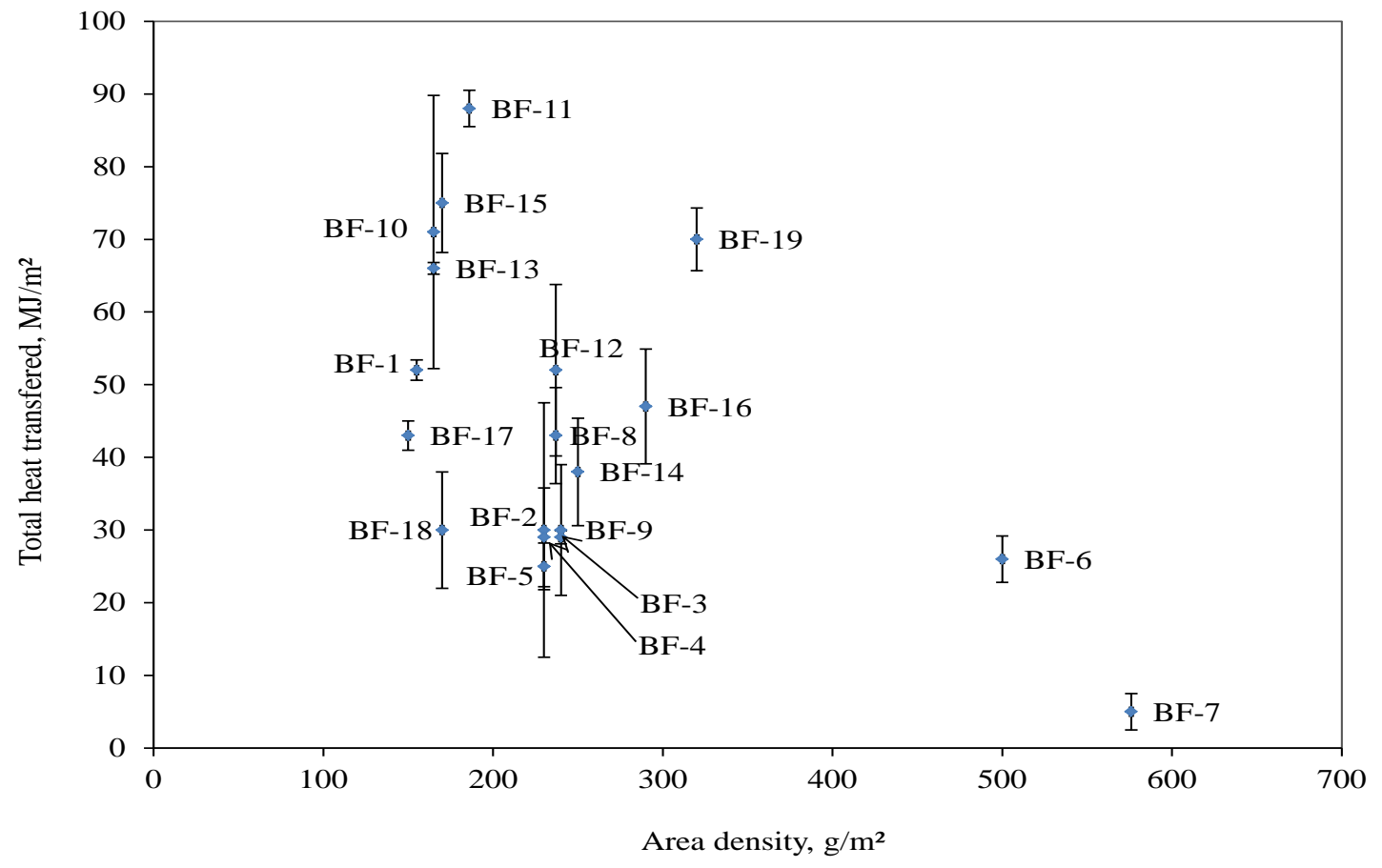

Figure 12. Correlation between THT and area density of the BFs. Uncertainties are reported as Type A uncertainties with experimental standard deviations.

Passive barrier materials BF-17, BF-18 and BF-19 have similar woven structures, fiber content, and thicknesses, but have different area densities. The amount of heat transferred and, hence, the thermal protective performance of these BFs containing inherently non-combustible glass fiber varies with the area density. The THT through BF-17 (area density $=150 \mathrm{~g} / \mathrm{m}^{2}$ ) was recorded as $43.3 \mathrm{MJ} / \mathrm{m}^{2} \pm 2 \mathrm{MJ} / \mathrm{m}^{2}$ whereas, BF-18 with higher area density $\left(170 \mathrm{~g} / \mathrm{m}^{2}\right)$ has a lower heat transfer rate and the THT during the $70 \mathrm{~s}$ exposure was $30 \mathrm{MJ} / \mathrm{m}^{2} \pm 8 \mathrm{MJ} / \mathrm{m}^{2}$. The amount of heat transferred through woven glass fiber fabrics decreased with increase in their area density. However, for BF-19 (320 g/m²), a significantly higher heat transfer rate was recorded. The high heat transfer rate of BF-19 could have been due to higher thermal conductivity [38] of the densely woven glass fiber fabric. This suggests that there is a critical area density above which the additional benefit in thermal protection gained by the increase in area density is offset by the increased efficiency of thermal conduction. 


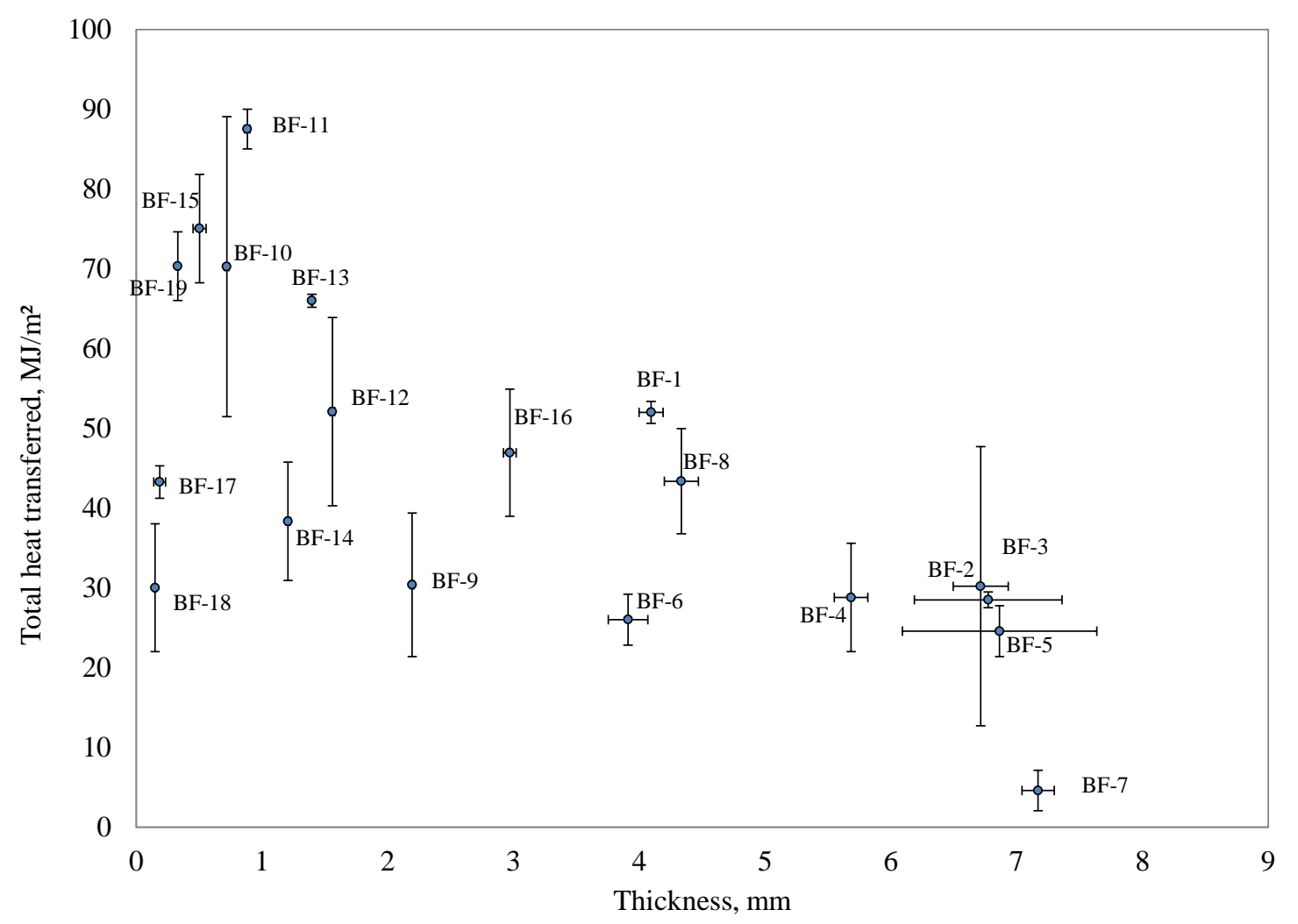

Figure 13. Correlation between THT and thickness of the BFs. Uncertainties are reported as Type A uncertainties with experimental standard deviations.

BF-15 and BF-18 had similar area densities, fiber content and woven construction. A lower amount of heat was transferred $\left(30 \mathrm{MJ} / \mathrm{m}^{2} \pm 8 \mathrm{MJ} / \mathrm{m}^{2}\right)$ through BF-18, compared to BF-15, which was $75 \mathrm{MJ} / \mathrm{m}^{2} \pm 7 \mathrm{MJ} / \mathrm{m}^{2}$. The higher heat transfer though BF-15 could be due to its higher porosity and hence higher permeability of the woven structure. The woven BF-15 was more porous than the densely woven glass fiber fabric (BF-18). The pore size impacts the rate of air permeability, which in turn impacts the convective heat transfer.

Such a trend is also seen among the knitted BFs (e.g., BF-11, BF-12, BF-13, and BF-14). With similar fiber content in BF-11 and BF-12, BF-11 showed higher heat transfer rates. BF-12 has a higher area density $\left(237 \mathrm{~g} / \mathrm{m}^{2}\right)$ as compared to BF-11 thereby inhibiting convective heat transfer. Amongst the knitted BFs, BF-14 with inherently fire resistant carbon fibers and with the highest area density $\left(270 \mathrm{~g} / \mathrm{m}^{2}\right)$ has very low heat transfer rates. The THT value recorded for BF-14 was $38 \mathrm{MJ} / \mathrm{m}^{2} \pm 7 \mathrm{MJ} / \mathrm{m}^{2}$.

Amongst the nonwoven BFs, BF-1 and BF-2 have similar fiber content and highloft construction. The difference in heat transfer properties of BF-1 and BF-2 is primarily due to the difference in their area densities and thickness. With a rise in temperature of about $150{ }^{\circ} \mathrm{C} / \mathrm{min} \pm$ $18^{\circ} \mathrm{C} / \mathrm{min}$ at the unexposed surface of BF-2, the THT value is recorded as $30 \mathrm{MJ} / \mathrm{m}^{2} \pm 17 \mathrm{MJ} / \mathrm{m}^{2}$. 
BF-1, however, has a higher heat transfer rate, and THT through BF-1 is recorded as $52 \mathrm{MJ} / \mathrm{m}^{2} \pm$ $1.4 \mathrm{MJ} / \mathrm{m}^{2}$. The residual char of BF-2 was pliable as opposed to the thin fragile char of BF-1.

Fiber type can be an equally important characteristic in nonwoven highloft BFs effectiveness. Nonwovens BF-2, BF-5, and BF-7 have similar thicknesses but different area densities and are constructed from different fiber blends. BF-5 has boric acid treated cotton fiber and shows significant enhancement in HTP. The rise in temperature at the unexposed surface of BF-5 is 1.7 times slower $\left(90^{\circ} \mathrm{C} / \mathrm{min}\right)$ as compared to that for BF-2 $\left(150{ }^{\circ} \mathrm{C} / \mathrm{min}\right)$. The higher heat transfer rate of BF-2 can be partly attributed to the high heat release rate (HRR) of FR viscose/polyester blends. In BF-5, the boric acid catalyzes dehydration reactions of cotton fibers and facilitates char formation [39]. When exposed to an open flame, the boric acid decomposes endothermically to release water and cool the flame [11]. The main drawback of BF-5 is that the residual char had several holes in it and this can have detrimental effects on the barrier effectiveness of a material. BF-7 is a nonwoven felt with the highest area density $\left(576 \mathrm{~g} / \mathrm{m}^{2}\right)$ and thickness $(7 \mathrm{~mm})$, and therefore lowest heat transfer rate, amongst all the BFs tested in this study. Moreover, the carbon fiber in BF-7 is inherently fire resistant and shows no signs of decomposition when exposed to a high heat flux of $65 \mathrm{~kW} / \mathrm{m}^{2}$. Compared to BF-7, a $43 \%$ thinner carbon fiber felt (BF-6, $4 \mathrm{~mm}$ thick) had 5 times higher heat transfer $\left(26.0 \mathrm{MJ} / \mathrm{m}^{2} \pm 2.5\right.$ $\mathrm{MJ} / \mathrm{m}^{2}$ ) suggesting a strong correlation between thickness and THT for BFs with similar characteristics (e.g., construction and fiber type). It is important to note here that the area densities of BF-6 and BF-7 are somewhat comparable.

The heat transfer characteristics of barrier materials depend on their thermal conductivity, density, thickness and thermal emissivity. In this study, thermal conductivity and thermal emission properties of barrier materials were not measured. However, the area density and thickness of BFs showed a strong influence on heat transfer properties. Thicker barrier materials with temperature gradients behaved as thermally thick barriers and resulted in lower heat transfer rates, whereas thermally thin barriers with constant temperatures throughout the depth of the material resulted in higher heat transfer rates. Thus, for better barrier effectiveness, the material should have sufficient thermal thickness.

In addition to BF thickness, density and construction, other factors that influence heat transfer include thermal conductivity and heat capacity of fibers, the nature of the boundary layer formed at the fabric air interface, the extent of endothermic reactions occurring in the solid or vapor phase, combustion products formed and their thermal properties [18]. The mechanism of heat transfer through BFs comprises a more complex combination of absorption and re-radiation, conduction and perhaps forced convection. Surface transfer coefficients and surface optical properties affect, respectively, the convective and radiative heat transfer to the surface of the fabric. The process of heat transfer through the fabric is also affected by bulk heat capacity, bulk conductivity, fiber-to-air ratio and air void distribution. It is therefore more meaningful to rank BFs using protective index. Reported in Table 3 are the BF weight normalized THT value, termed as heat transfer factor (HTF) having units of J/g. HTF is the ratio of the THT value to the fabric area density in $\mathrm{g} / \mathrm{m}^{2}$. The inverse of HTF can be arbitrarily defined as the thermal protective index (TPI) of BF. The ranking of BFs using protective indices is shown in Figure 14. Depending on the thermal thickness and fiber content, different BF types yielded different TPI values. The higher the TPI value, the better is the thermal protective performance of a BF. 


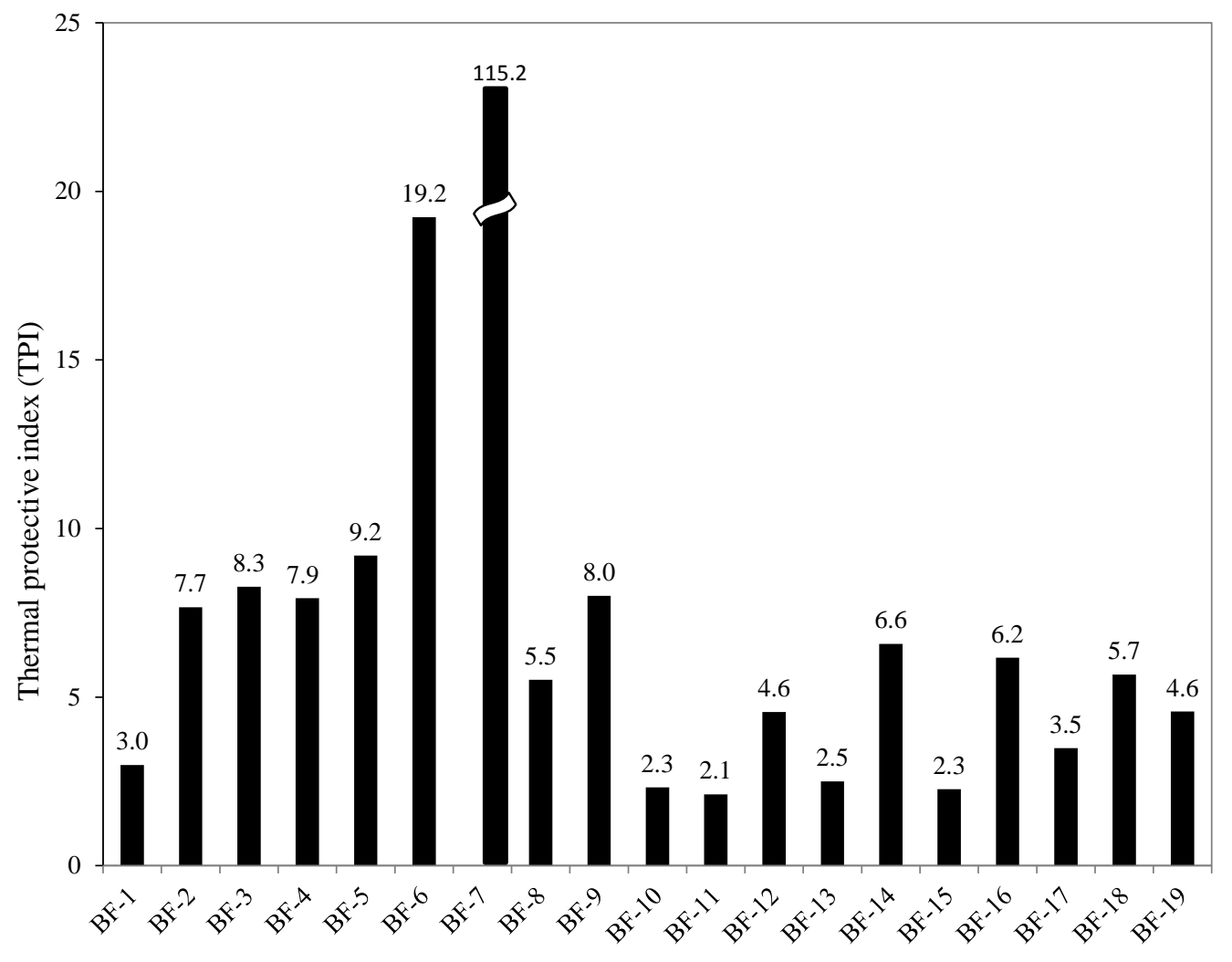

Figure 14. Ranking of BFs using thermal protective indices.

\subsection{Flammability of BFs}

Numerous researchers[31,30,40,41] have shown that cone calorimeter measurements on materials such as those considered in the current study can provide significant experimental challenges associated with the materials' low mass, thickness, and burning behavior. Various approaches for improving the reliability and reproducibility of the measurements have been discussed. These same sample properties often lead to periods of heat release in typical cone calorimeter experiments that last on the order of seconds or tens of seconds. Such heat release times are comparable to the response times of most cone calorimeters, with a value of close to $6 \mathrm{~s}$ being typical. Recorded HRRs are known to be distorted from the actual time behavior when rapid changes take place over periods comparable to the response time. For the sharp peaks characteristic of these experiments, measured values of maximum HRR would be expected to underestimate the actual value, while the time required to reach the maximum value would be overestimated.

The sample holder system shown in Figure 6 was designed to minimize problems associated with testing fabrics and barrier materials. Even though approaches have been developed for correcting for time response effects $[30,42,43,44]$, such corrections were judged to be beyond the scope of this project, and the following results are based on the experimental data as 
recorded. As a result, the findings represent relative characterizations of BFs and should not be considered as absolute values.

Various parameters derived from the cone calorimeter data including ignition times, peak heat release rate, time to peak heat released (TTP), total heat released, FIGRA indices, and char yield are given in Table 4 for the various BFs. All the BFs had relatively short TTI values, but selfextinguished quickly (flame out (FO) time $\leq 50 \mathrm{~s}$ ), have low PHRR, low TTP, and low THR values. The residual char after combustion was measured, and most BFs had at least $40 \%$ of their original mass retained. Moreover, experimental times for such materials are relatively short where burning takes place at a high rate before the sample self-extinguishes.

Table 4. Flammability properties of BFs under fully-ventilated conditions in the cone calorimeter . Uncertainties in measurement of PHRR and THR are reported as Type A uncertainties with experimental standard deviations.

\begin{tabular}{|c|c|c|c|c|c|c|c|}
\hline Sample & TTI, $\mathbf{s}$ & FO, $\mathbf{s}$ & $\begin{array}{c}\text { PHRR, } \\
\mathbf{k W} / \mathbf{m}^{\mathbf{2}}\end{array}$ & TTP, $\mathbf{s}$ & $\begin{array}{c}\text { FIGRA, } \\
\mathbf{k W / s}\end{array}$ & Char yield, $\mathbf{~}$ & THR, kJ \\
\hline BF-1 & 6 & 24 & $134 \pm 11$ & 10 & 13.4 & 40 & $19 \pm 4.0$ \\
\hline BF-2 & 4 & 50 & $137 \pm 3$ & 6 & 22.8 & 39 & $43 \pm 0.7$ \\
\hline BF-3 & 4 & 34 & $104 \pm 4$ & 7 & 14.8 & 42 & $31 \pm 2.6$ \\
\hline BF-4 & 5 & 33 & $108 \pm 4$ & 8 & 13.5 & 37 & $35 \pm 2.3$ \\
\hline BF-5 & 6 & 35 & $108 \pm 6$ & 8 & 13.5 & 38 & $44 \pm 5.2$ \\
\hline BF-6 & 11 & 36 & $6 \pm 1$ & 8 & 0.8 & 68 & $32 \pm 3.3$ \\
\hline BF-7 & - & - & - & - & - & - & - \\
\hline BF-8 & 6 & 28 & $22 \pm 1$ & 13 & 1.7 & 21 & $41 \pm 12$ \\
\hline BF-9 & 6 & 30 & $143 \pm 8$ & 12 & 11.9 & 35 & $25 \pm 1.6$ \\
\hline BF-10 & 4 & 20 & $102 \pm 8$ & 11 & 9.3 & 42 & $17 \pm 1.7$ \\
\hline BF-11 & 8 & 10 & $74 \pm 32$ & 11 & 6.7 & 61 & $14 \pm 3.2$ \\
\hline BF-12 & 8 & 10 & $115 \pm 3$ & 12 & 9.6 & 58 & $23 \pm 1.8$ \\
\hline BF-13 & 7 & 12 & $141 \pm 10$ & 12 & 11.8 & 43 & $16 \pm 0.9$ \\
\hline BF-14 & 10 & 20 & $14 \pm 1$ & 14 & 1.0 & 46 & $40 \pm 2.2$ \\
\hline BF-15 & 7 & 10 & $7 \pm 4$ & 10 & 0.7 & 73 & $9 \pm 3$ \\
\hline BF-16 & 6 & 38 & $186 \pm 20$ & 12 & 15.5 & 43 & $27 \pm 5.4$ \\
\hline BF-17 & - & - & - & - & - & - & - \\
\hline BF-18 & - & - & - & - & - & - & - \\
\hline BF-19 & 8 & 10 & $6 \pm 1$ & 8 & 0.8 & 78 & $7 \pm 0.8$ \\
\hline
\end{tabular}

- Not tested due to limited sample availability.

In general, the TTI data suggests that the physical thickness does not influence the time to ignition of BFs under a given set of conditions. Time to ignition is higher for BFs containing inorganic fibers e.g., BF-6, BF-14, and BF-19. Barrier fabrics BF-6, BF-14, BF-15 and BF-19 have small flaming periods and very low PHRRs $\left(<15 \mathrm{~kW} / \mathrm{m}^{2}\right)$ due to the presence of inherently fire resistant fibers. BFs containing organic fibers (BF-1, BF-2, BF-3, BF-4, BF-5, BF-9, BF-10, BF-12, BF-13, and BF-16) burn with PHRR values in excess of $100 \mathrm{~kW} / \mathrm{m}^{2} \pm 10 \mathrm{~kW} / \mathrm{m}^{2}$ with the exception of BF-8. BF-8 has a very small PHRR value of $22 \mathrm{~kW} / \mathrm{m}^{2} \pm 1 \mathrm{~kW} / \mathrm{m}^{2}$. BF-8 is a blend of FR rayon/proprietary inorganic fiber/polyester and has higher area density $\left(\sim 240 \mathrm{~g} / \mathrm{m}^{2}\right)$ with low thickness $(4 \mathrm{~mm})$. The proportion of inorganic fibers to the FR rayon fibers is proprietary, but the lower PHRR values suggest significant fraction of inorganic fibers in the blend. FIGRA 
values distinguishes BFs containing inorganic fire resistant fibers (FIGRA $<2 \mathrm{~kW} / \mathrm{s}$ ), BFs with active flame retardants (FIGRA $<10 \mathrm{~kW} / \mathrm{s}$ ), and passive BFs (FIGRA $>10 \mathrm{~kW} / \mathrm{s}$ ).

\subsection{Burning behavior of composite assemblies}

Digital images of composite assemblies that exhibited self-extinguishing behavior when exposed to a $40 \mathrm{~mm}$ butane flame for $20 \mathrm{~s}$ in a modified Mydrin test are shown in Table 5. For all composites tested, the initial flame spread was tilted slightly from vertical due to the direction of air flow in the exhaust system. All the composite assemblies in Table 5 had active BFs. As mentioned earlier, active BFs not only help prevent the ignition of interior foam but can also prevent the outer upholstery, i.e., ticking or cover fabric, from burning.

Although BF-10 has a relatively high heat transfer rate when exposed to combined radiant and convective heat fluxes (see Table 3), the composite sample with the BF-10 barrier selfextinguishes when exposed to the open flame ignition source for $20 \mathrm{~s}$. Under forced burning conditions, as in cone calorimetry, BF-10 had a PHRR of $102 \mathrm{~kW} / \mathrm{m}^{2} \pm 8 \mathrm{~kW} / \mathrm{m}^{2}$ and the sample burned with a char yield of $42 \%$ (see Table 4). The active (vapor phase) FR mechanism is operational only when the FR sample is exposed to an open flame. BF-11 is a knitted barrier using core spun yarn with a glass fiber filament and sheath fibers of modacrylic made from acrylonitrile and vinylidene chloride. The modacrylic fiber contains an antimony catalyst as an additive. The sheath fiber imparts active flame retardancy to the BF. Despite being thermally thin with high air permeability, all active barrier fabrics (BF-10, BF-11, BF-12 and BF-15) acted as very good fire blocking fabrics when exposed to open flame ignition.

Digital images of composite samples with passive BFs exposed to a $40 \mathrm{~mm}$ butane flame for $20 \mathrm{~s}$ are shown in Table 6. In general, these passive BFs prevent or delay the ignition of the interior foam; however, they do not prevent burning of the outer ticking or cover fabric. The duration of flaming for these composite assemblies is generally between $2 \mathrm{~min}$ and $4 \mathrm{~min}$. Those with longer durations of flaming were extinguished manually. Ignoring the edge effects, most of these BFs burn with the ticking and form a char in place. The extent of damage to the underlying foam primarily depends on the type and structure of the charred barrier material, which in turn depends on fiber content, structural attributes, and thickness of the BF. Composite assemblies tested with BF-5, BF-6 and BF-7 showed very little or no damage to the foam. Amongst the carbon fiber barrier materials, the knitted structure in BF-14 failed to protect the underlying foam. However, it can be noted from the images that the BF failed mainly at the edges. The more porous structure of the knitted BF-14 failed to protect the foam at the edges. The heat transfer in the case of BF-14 is also much higher than for BF-6 and BF-7. Thus it can be seen that if the $\mathrm{BF}$ is not an active fire barrier, then the amount of heat transfer through a barrier is critical, i.e, the material should be thermally thick to protect the underlying foam. The extent of damage to the foam was much greater in the case of thermally thin barrier materials with no active flame retardants (e.g., BF-8, BF-9, BF-13, BF-16, BF-17, BF-18, and BF-19).

Digital images of PUF/BF composite assemblies tested without ticking are shown in Table 6. The composite assemblies were exposed to a butane flame for $40 \mathrm{~s}$ and the burning behavior was noted. In the absence of ticking, all PUF/BF composite assemblies exhibited self-extinguishing behavior. Depending on the type of BF, the extent of thermal damage to the PUF was evident 
from this experiment. Stratified BF-4 containing boric acid treated cotton and FR rayon performed best to protect the foam. Thermally thin, glass fiber containing barrier materials e.g., BF-17, BF-18, and BF-19 conducted greater heat to the PUF and hence there was more thermal damage to the foam, as seen in Table 6. However, thermal degradation of the foam was not significant enough to be able to support combustion. The differences between the various BFs with regard to after-flaming time and char lengths were not considered to be particularly significant. 
Table 5. Digital images of composite samples with active BFs exposed to $40 \mathrm{~mm}$ butane flame for $20 \mathrm{~s}$.

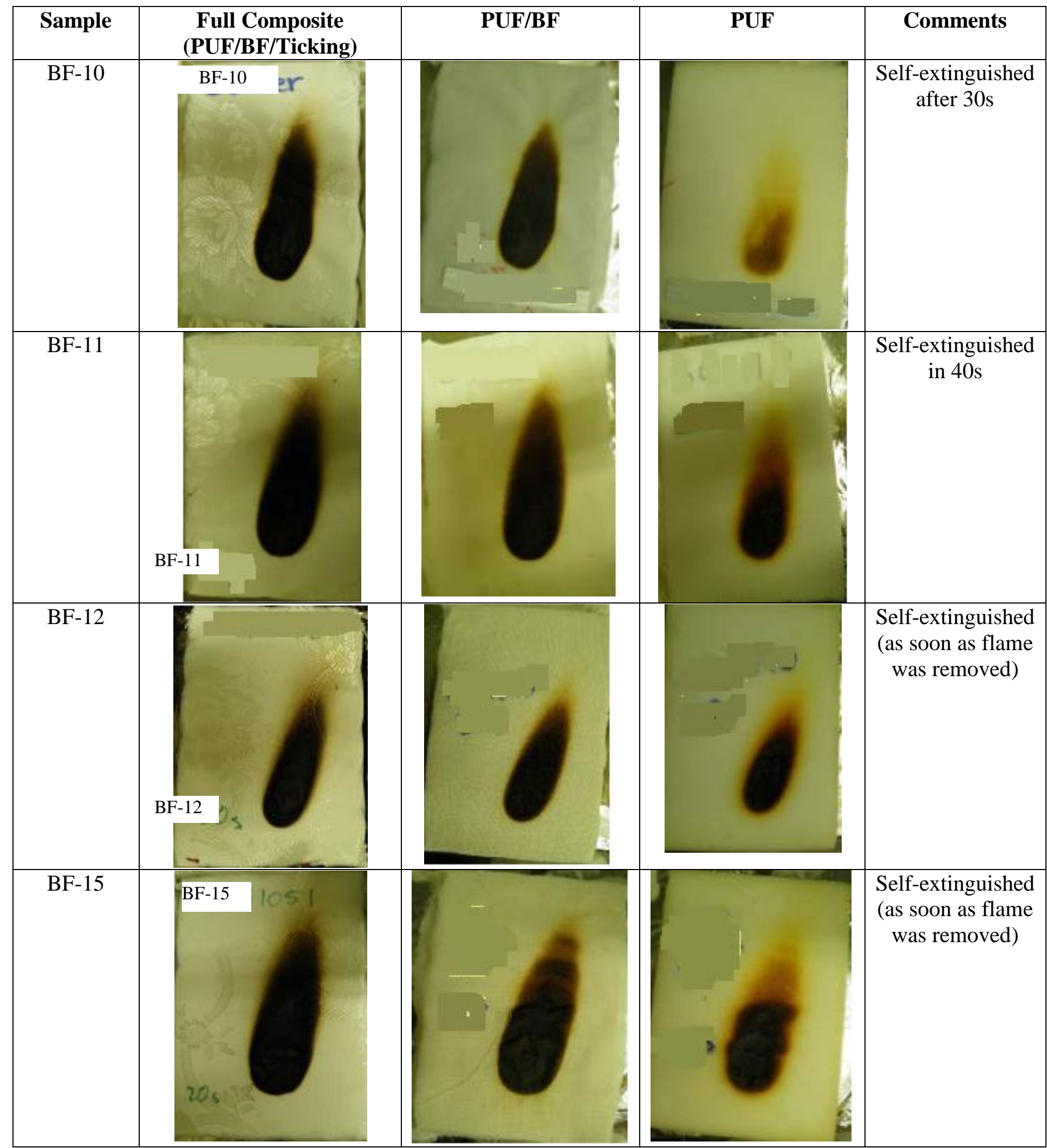


Table 6. Digital images of composite samples with passive BFs exposed to $40 \mathrm{~mm}$ butane flame for $20 \mathrm{~s}$.

\begin{tabular}{|c|c|c|c|c|c|c|c|}
\hline \multirow[t]{2}{*}{ Sample } & \multicolumn{5}{|c|}{ Full composite samples tested with ticking } & \multicolumn{2}{|c|}{$\begin{array}{c}\text { Composite samples tested* } \\
\text { without ticking }\end{array}$} \\
\hline & $\begin{array}{c}\text { Full Composite } \\
\text { (PUF/BF/Ticking) }\end{array}$ & PUF/BF & PUF & $\begin{array}{c}\text { Duration of } \\
\text { flaming, min }\end{array}$ & Comments & PUF/BF & PUF \\
\hline BF-1 & & & & 2.3 & $\begin{array}{c}\text { Self } \\
\text { extinguished }\end{array}$ & & \\
\hline BF-2 & & & & 3.5 & $\begin{array}{c}\text { Self } \\
\text { extinguished }\end{array}$ & \multicolumn{2}{|c|}{ Fail, foam catches fire } \\
\hline BF-3 & & & $\underline{x}$ & 3.4 & $\begin{array}{c}\text { Self } \\
\text { extinguished }\end{array}$ & \multicolumn{2}{|c|}{ Not Tested (N/T) } \\
\hline \multirow[t]{2}{*}{ BF-4 } & & & 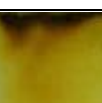 & 3.4 & $\begin{array}{c}\text { Self } \\
\text { extinguished }\end{array}$ & & \\
\hline & & & & & & \multicolumn{2}{|c|}{$\begin{array}{l}\text { Self-extinguished as soon as flame } \\
\text { was removed }\end{array}$} \\
\hline
\end{tabular}


Table 6. Continued.

\begin{tabular}{|c|c|c|c|c|c|c|c|}
\hline \multirow[t]{2}{*}{ Sample } & \multicolumn{5}{|c|}{ Full composite samples tested with ticking } & \multicolumn{2}{|c|}{$\begin{array}{l}\text { Composite samples tested* } \\
\text { without ticking }\end{array}$} \\
\hline & $\begin{array}{l}\text { Full Composite } \\
\text { (PUF/BF/Ticking) }\end{array}$ & PUF/BF & PUF & $\begin{array}{l}\text { Duration of } \\
\text { flaming, min }\end{array}$ & Comments & PUF/BF & PUF \\
\hline BF-5 & & & & 3.3 & $\begin{array}{c}\text { Self } \\
\text { extinguished }\end{array}$ & \multicolumn{2}{|c|}{$\mathrm{N} / \mathrm{T}$} \\
\hline BF-6 & & & & 4.0 & $\begin{array}{c}\text { Self } \\
\text { extinguished }\end{array}$ & \multicolumn{2}{|c|}{$\mathrm{N} / \mathrm{T}$} \\
\hline BF-8 & & & & $<4.0$ & Foam ignites & $\begin{array}{l}\text { Self-extinguished } \\
\text { as soon as flame } \\
\text { was removed }\end{array}$ & \\
\hline BF-9 & & & & 4.5 & $\begin{array}{c}\text { Self } \\
\text { extinguished }\end{array}$ & & \\
\hline & & & & & & $\begin{array}{r}\text { Self-extinguished } \\
\text { was rer }\end{array}$ & on as flame \\
\hline
\end{tabular}


Table 6. Continued..

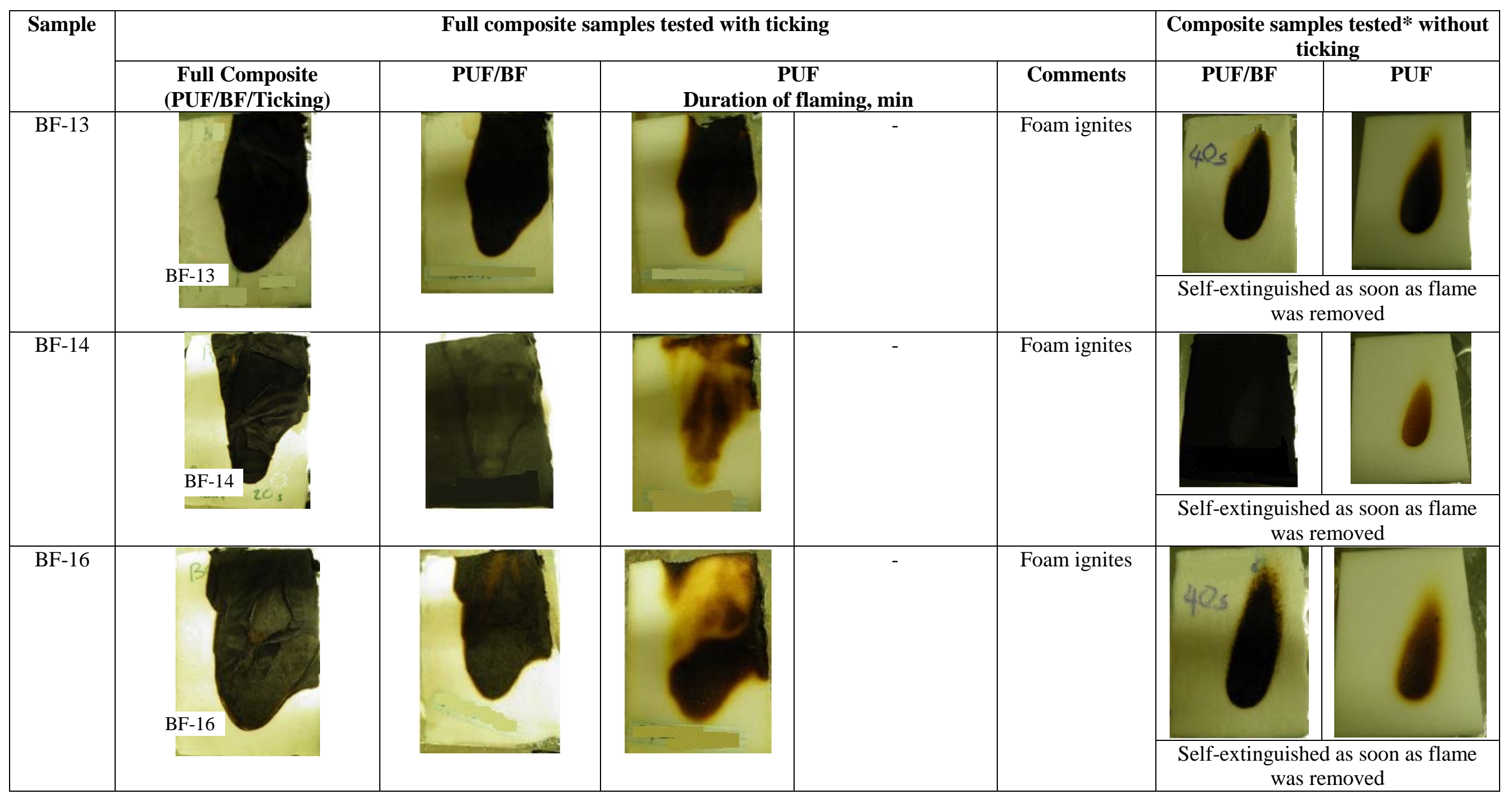


Table 6. Continued..

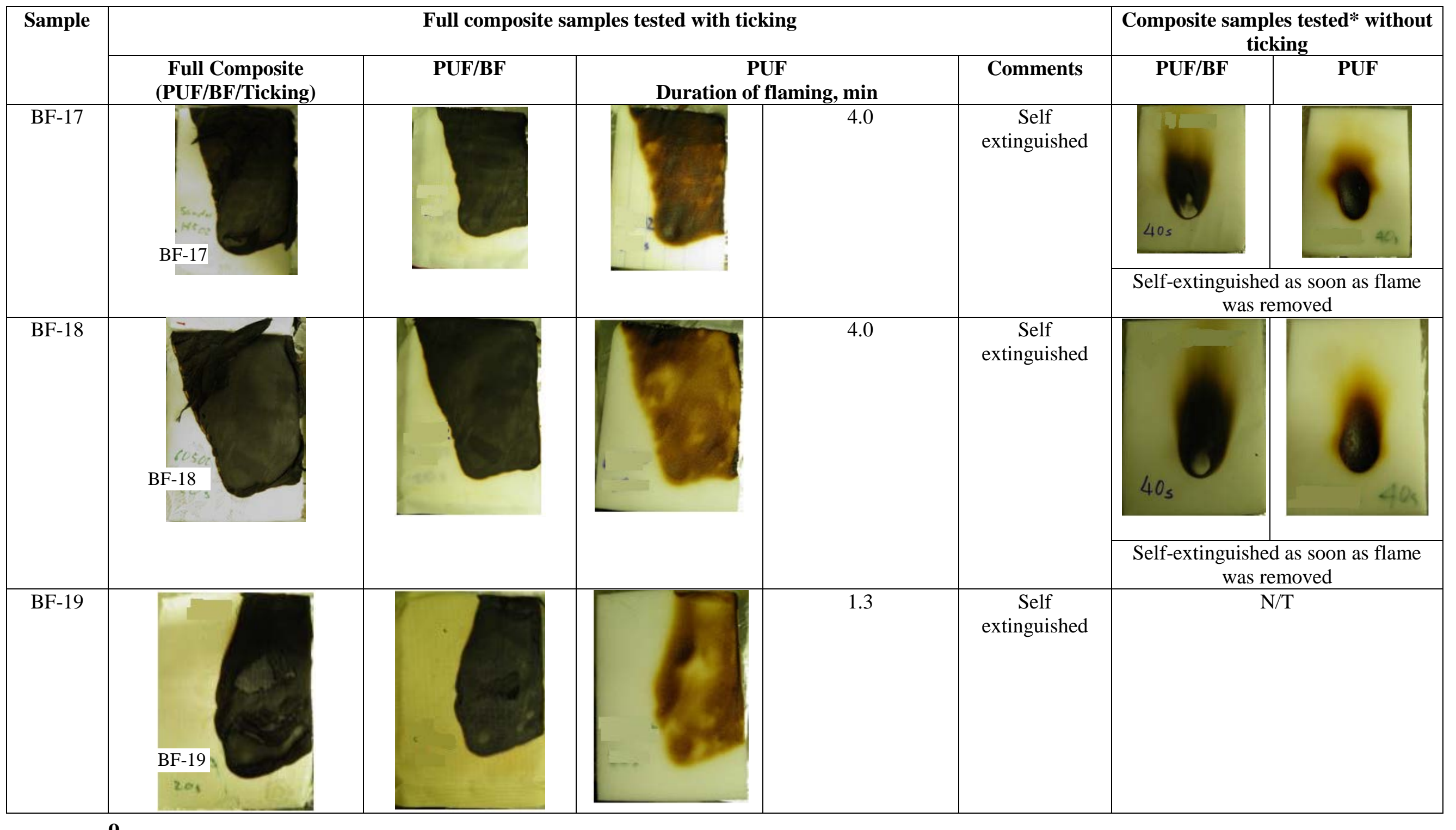




\section{Concluding Remarks and Future Work}

The purpose of a BF is to limit the cushioning material involvement in a fire by preventing and/or significantly delaying the ignition of core materials, lowering the heat release rate, reducing the rate of flame spread and/or extinguishing the flames. BFs must limit the heat transfer into the interior foam via conduction, convection, and radiation.

This work has demonstrated that the modified TPP test method allows critical BF heat transfer characteristics to be monitored and provides fundamental insight into BF thermal response as it relates to thermal protection of cushioning components (e.g., PUF) in upholstered products. Thus, measurements of heat transfer rate in BFs are useful in assessing their effectiveness as fire barrier materials.

When tested for heat transfer characteristics, the area density and thickness of BFs have a strong influence. However, when tested as a composite in a mock-up assembly, the fire blocking barrier materials considered in this study showed a clear distinction between active and passive BFs. In the case of active BFs, the construction parameters and material properties such as thickness, air permeability, and heat transfer were of little significance. However, in the case of passive BFs, these parameters became decisive. Results from this study suggests that if the BF is not an active fire barrier, then the amount of heat transferred through BF is critical, i.e, the material should be thermally thick to protect the underlying foam.

BFs used in soft furnishings are generally porous materials. The size of the pores defines the rate of air permeability, which in turn impacts the pyrolysis rate of materials within the barrier. The permeability should be low enough to prevent flaming combustion inside the BF, especially when pyrolysis gases accumulate underneath the barrier. Permeability of a BF before and after heat exposure should provide insight into changes in porosity and whether or not the material will act as an effective barrier to gas exchanges. The other important measurement that would give deeper understanding into how BFs degrade in a TPP test is the retention of bulk density after exposure. Changes in BF density reflect changes in thickness and weight caused by pyrolysis and shrinkage effects during heat exposure. Since density is a critical quantity in a transient heat transfer measurements, these changes would be of greater interest.

BFs, when exposed to a fire, develop significant fire induced stresses and deformations, which should be properly accounted for in evaluating realistic response of barrier materials. Measurement of the breaking strength of BFs exposed to various heat fluxes may provide insight into the loss of tensile strength due to heat exposure.

The composite bench-scale test employed for this study is still in the developmental stage. The test method has its limitations with respect to sample size, edge effects, and orientation of the sample. Furthermore, PUF as a filling material has long shown high variability in such type of composite tests and requires extensive replication in order to obtain satisfactory results. Reproducibility and repeatability of the test therefore needs to be addressed. 
Since many factors can contribute to the capability of a given material to meet requirements of a $\mathrm{BF}$, general principles for selecting BFs and engineering their fire safety need to be established. To engineer upholstered product safety, the BFs must be resistant to smoldering ignition sources as well as to open flames. Smoldering ignition studies of these BFs are currently in progress and will be the subject of a subsequent report. In developing further principles for engineering fire safety of BF, we propose two fundamental principles as important technical considerations. Firstly, BF is protective in its function and therefore it must not become involved in burning during its protective function. Secondly, the BF must be instrumental in extinguishing flames from burning of cover fabrics or tickings. Third, the BF must either provide adequate insulation to reduce heat transfer or have low permeability so as to limit rate of pyrolysis underneath the barrier.

With regards to test methods for evaluating BFs, both vertical flame test and methods based on heat release have proved insufficient. Ranking of BFs based on heat transfer measurements seems acceptable. Further study is required to look at longer duration exposures and to probe the mechanisms of degradative heat transfer. Correlation between a bench-scale mock-up and largescale, if not full-scale, product testing is also required. 


\section{References}

[1] 16 CFR Part 1633 Standard for the flammability (open flame) of mattress sets. Consumer Product Safety Commission. March (2007). Available from: http://www.cpsc.gov/businfo/frnotices/fr06/mattsets.pdf.

[2] Damant G. Use of fire blocking and barrier systems to comply with fire tests for furnishings, Proceedings of the twelfth international conference INTERFLAM 2010, Interscience Communications, West Yard House, Guildford Grove Greenwich, London, UK. ISBN 978-0-9541216-5-5 (Vol 1).

[3] 16 CFR Part 1634, Standard for the flammability of residential upholstered furniture (proposed rule). Consumer Product Safety Commission. March (2008). Available from: http://www.cpsc.gov/businfo/frnotices/fr08/furnflamm.pdf.

[4] Nazare S and Davis R. A review of fire blocking technologies for soft furnishings, NIST TN 1728, November 2011, National Institute of Standards and Technology, Gaithersburg MD. Published in Fire Science Reviews 2012, 1:1 (23 April 2012)

[5] Upholstery Furniture Action Council, UFAC Central Box 2436 High Point, NC 27261 http://www.ufac.org/method1.htm

[6] BS 5852:2006 Methods of test for assessment of the ignitability of upholstered seating by smoldering and flaming ignition sources. British Standards Institution, London, UK.

[7] Upholstery Furniture Action Council, UFAC Central Box 2436 High Point, NC 27261 http://www.ufac.org/method3.htm

[8] ASTM E1353-08a, standard test method for cigarette ignition resistance of components of upholstered furniture. ASTM Standards for Upholstered Furniture, Mattresses and Bedding, ASTM International, 100 Barr Harbor Drive, PO Box C700, West Conshohocken, PA 19428-2959.

[9] NFPA 260 Standard methods of tests and classification system for cigarette ignition resistance of components of upholstered furniture, National Fire Protection Association (NFPA), 1 Batterymarch Park, Quincy, MA 02269-9101 USA.

[10] ASTM D5238 - 10 Standard test method for smoldering combustion potential of cottonbased batting. ASTM Standards for Upholstered Furniture, Mattresses and Bedding, ASTM International, 100 Barr Harbor Drive, PO Box C700, West Conshohocken, PA 19428-2959.

[11] Wakelyn PJ, Wolf S, Oliver K. Cotton batting fire-blocking barriers for soft furnishings. Presented at the $14^{\text {th }}$ Annual Business Communications Company, Inc. (BCC) Conference on Flame Retardancy June 3, 2003. Stamford, CT.

[12] California TB 117-2013, Requirements, Test Procedures and Apparatus for Testing the Flame Retardance of Resilient Filling Materials Used in Upholstered Furniture. State of California Department of Consumer Affairs, Bureau of Electronic and Appliance Repair Home Furnishings and Thermal Insulation, 4244 South Market Court, Suite D, Sacramento, CA 95834-1243.

[13] California TB 116, Requirements, Test Procedure and Apparatus for Testing the Flame Retardance of Upholstered Furniture. State of California Department of Consumer Affairs, Bureau of Electronic and Appliance Repair Home Furnishings and Thermal Insulation, 4244 South Market Court, Suite D, Sacramento, CA 95834-1243. 
[14] ASTM D7140 - 07 Standard test method to measure heat transfer through textile thermal barrier materials. ASTM Standards for Upholstered Furniture, Mattresses and Bedding, ASTM International, 100 Barr Harbor Drive, PO Box C700, West Conshohocken, PA 19428-2959.

[15] Wallace M, Fire Barriers for Furnishings - Progress in Technologies and Fire Performance Testing of Barrier Fabrics Intended for Mattress and Upholstery Furniture Industries, Presented at NIST Fire Barrier Workshop, March 18 - 19, 2009.

[16] Combs HE. Proposed California rule has 3 new FR tests. In Furniture Today, August 2012. Available from http://www.furnituretoday.com/article/554143-

Proposed_California_rule has_3_new_FR tests.php

[17] Shalev I and Barker R. Protective fabrics: A comparison of laboratory methods for evaluating thermal and protective performance in convective/radiant exposures. Textile Research Journal. 1984; 54: 648-654.

[18] Shalev I and Barker RL. Analysis of heat transfer characteristics of fabrics in an open flame exposure. Textile Research Journal 1983; 475-482.

[19] Stoll AM, and Chianta MA. A method and rating system for evaluation of thermal protection, Aerospace Medicine 1969; 40 (11):1232-1238.

[20] NFPA 1971: Standard on protective ensembles for structural fire fighting and proximity fire fighting. National Fire Protection Association, Quincy, Massachusetts , 2007 Edition.

[21] Shalev I and Barker RL. Predicting the thermal protective performance of heat-protective fabrics from basic properties. Performance of protective clothing. ASTM STP 900, R.L. Barker and G.C. Coletta, Eds;, American Society for Testing and Materials, Philadelphia, 1986: 358-375.

[22] Capacitive sensor operation and optimization. St. Paul, MN: Lion Precision. Retrieved June 6, 2012, from www.lionprecision.com

[23] Shields TJ, Silock GW, Murray JJ. Evaluating ignition data using the flux time product. Fire and Materials. 1994; 18 (4): 243-254.

[24] Ohlemiller T, and Shields J. One- and two-sided burning of thermally thin materials. Fire and Materials. 1993; 17 (3): 103-110.

[25] Ohlemiller TJ, Shields J, McLane R and Gann R. Flammability assessment methodology for mattresses, NIST Internal Report 6497, June 2000. National Institute of Standards and Technology, Gaithersburg MD.

[26] Ohlemiller TJ. Flammability test of full-scale mattresses: Gas burners versus burning bedclothes, NIST Internal Report 7006, July 2003. National Institute of Standards and Technology, Gaithersburg MD.

[27] 16 CFR 1663 Standard for the flammability of. Consumer Product Safety Commission, USA, July 2007.

[28] Hoschke BN, Holcombe BV, Plante AM. A critical appraisal of test methods for thermal protective clothing fabrics. Performance of protective clothing, ASTM STP 900, R.L. Barker and G.C. Coletta, EDs., ASTM, Philadelphia, 1986, pp. 311-326.

[29] ISO 5660-1:2002 Reaction-to-fire tests -- Heat release, smoke production and mass loss rate- Part 1: Heat release rate (cone calorimeter method).

[30] Nazaré S, Kandola B, Horrocks AR. Use of cone calorimetry to quantify the burning hazard of apparel fabrics. Fire and Materials. 2002; 26: 191-199. 
[31] Schartel B and Hull TR. Development of fire-retarded materials-Interpretation of cone calorimeter data. Fire and Materials. 2007; 31(5): 327-354.

[32] Horrocks, A.R. and Kandola B., Flammability testing of textiles, Chapter 6, in Plastics Flammability Handbook, Troitzsch J., (Editor), Hanser Publication, Munich 173-188, (2004).

[33] Wang MY, Horrocks AR, Horrocks S, Hall ME, Pearson JS, Clegg S. Flame retardant textile back-coatings. Part 1: Antimony-halogen system interactions and the effect of replacement by phosphorus-containing agents, Journal of Fire Sciences. 2000;18: 265 294.

[34] BS5852: 1979, British Standard Methods of Test for the Ignitability of Upholstered Composites for Seating, British Standards Institution, London.

[35] BS 5438: 1989, Methods of test for Flammability of textile fabrics when subjected to a small igniting flame applied to the face or bottom edge of vertically oriented specimens. British Standards Institution, London, UK.

[36] Zammarano M, Matko S, Kraemer RH, Davis RD, Gilman JW, Mehta SN, Factors influencing the smoldering performance of polyurethane foam, NIST TN 1747, September 2012. National Institute of Standards and Technology, Gaithersburg MD.

[37] 16 CFR Part 1632 Standard for the flammability of mattresses and mattress pads. Consumer Product Safety Commission. May (1991). Available from: http://www.cpsc.gov/businfo/testmatt.pdf.

[38] Benisek L, Edmondson GK, and Philips WA. Protective clothing-evaluation of wool and other fabrics. Textile Research Journal 1979; 212-220.

[39] Dombrowski R. Flame retardants for textile coatings, Journal of Coated Fabrics 1996; 25: 224-238.

[40] Tata J, Alongi J and Frache A. Optimization of the procedure to burn textile fabrics by cone calorimeter: Part I. Combustion behavior of polyester. Fire and Materials 2011; 35(6): 397-409.

[41] Lindholm J, Brink A and Hupa M. Influence of decreased sample size on cone calorimeter results. Fire and Materials 2012; 36 (1): 63-73.

[42] Lyon R E, Abramowitz A. Effect of instrument response time on heat release rate measurements. Fire and Materials 1995; 19 (1):11-17.

[43] Messerschmidt B, van Hess P. Influence of delay times and response times on heat release measurements. Fire and Materials 2000; 24 (2):121-130.

[44] Pitts, WM. Applied heat flux distribution and time response effects on cone calorimeter characterization of a commercial flexible foam. Fire Technology 2011; DOI: 10.1007/s10694-011-0235-8. 